\title{
Future change of Asian-Australian monsoon under RCP 4.5 anthropogenic warming scenario
}

\author{
Bin Wang $\cdot$ So-Young Yim $\cdot$ June-Yi Lee $\cdot$ \\ Jian Liu $\cdot$ Kyung-Ja Ha
}

Received: 1 August 2012/Accepted: 8 April 2013/Published online: 30 April 2013

(C) The Author(s) 2013. This article is published with open access at Springerlink.com

\begin{abstract}
We investigate the future changes of AsianAustralian monsoon (AAM) system projected by 20 climate models that participated in the phase five of the Coupled Model Intercomparison Project (CMIP5). A metrics for evaluation of the model's performance on AAM precipitation climatology and variability is used to select a subset of seven best models. The CMIP5 models are more skillful than the CMIP3 models in terms of the AAM metrics. The future projections made by the selected multimodel mean suggest the following changes by the end of the 21 st century. (1) The total AAM precipitation (as well as the land and oceanic components) will increase significantly (by $4.5 \% /{ }^{\circ} \mathrm{C}$ ) mainly due to the increases in Indian summer monsoon $\left(5.0 \% /{ }^{\circ} \mathrm{C}\right)$ and East Asian summer monsoon $\left(6.4 \% /{ }^{\circ} \mathrm{C}\right)$ rainfall; the Australian summer monsoon rainfall will increase moderately by $2.6 \% /{ }^{\circ} \mathrm{C}$.
\end{abstract}

\section{B. Wang}

Department of Meteorology, University of Hawaii at Manoa, Honolulu, HI 96825, USA

B. Wang $\cdot$ S.-Y. Yim $\cdot$ J.-Y. Lee

International Pacific Research Center, University of Hawaii at Manoa, Honolulu, HI 96825, USA

J.-Y. Lee $(\bowtie)$

University of Hawaii/IPRC, POST Bldg, Room 409E,

1680 East-West Road, Honolulu, HI 96822, USA

e-mail: jylee@soest.hawaii

\section{J. Liu}

Key Laboratory of Virtual Geographic Environment of Ministry of Education, School of Geography Science, Nanjing Normal University, Nanjing 210023, China

K.-J. Ha

Division of Earth Environmental System, Pusan National

University, Busan, South Korea
The "warm land-cool ocean" favors the entire AAM precipitation increase by generation of an east-west asymmetry in the sea level pressure field. On the other hand, the warm Northern Hemisphere-cool Southern Hemisphere induced hemispheric SLP difference favors the ASM but reduces the Australian summer monsoon rainfall. The combined effects explain the differences between the Asian and Australian monsoon changes. (2) The low-level tropical AAM circulation will weaken significantly (by $2.3 \% /$ ${ }^{\circ} \mathrm{C}$ ) due to atmospheric stabilization that overrides the effect of increasing moisture convergence. Different from the CMIP3 analysis, the EA subtropical summer monsoon circulation will increase by $4.4 \% /{ }^{\circ} \mathrm{C}$. (3) The Asian monsoon domain over the land area will expand by about $10 \%$. (4) The spatial structures of the leading mode of interannual variation of AAM precipitation will not change appreciably but the ENSO-AAM relationship will be significantly enhanced.

Keywords Asian-Australian monsoon - Global warming · Future change · CMIP5 - Multi-model mean · Interannual variation $\cdot$ ENSO-monsoon relationship

\section{Introduction}

Physically, monsoon is a forced response of the coupled atmosphere-land-ocean climate system to the annual variation of insolation. The response yields a unique monsoon climate regime characterized by an annual reversal of surface winds and contrasting rainy summer and dry winter. In contrasting to the traditional definition of monsoon using surface winds (Ramage 1971), recent studies define monsoon domains in terms of the precipitation characteristics (Wang 1994). The obtained monsoon precipitation 
domains include all regional monsoons over South Asia, East Asia, western North Pacific (WNP), Australia, Africa and Americas (Wang and Ding 2008).

Land-sea thermal contrast, topography, moist processes, and Earth's rotation determine monsoon rainfall patterns and vigor (Webster 1987). The huge seasonal variation in the thermal contrast between the largest Eurasian landmass and the Pacific-Indian Oceans drives the Asian monsoon which is the strongest annual cycle on Earth. The Asian monsoon, together with its Southern Hemisphere (SH) counterpart, the Indonesian-Australian monsoon (or Australian monsoon for short), forms an Asian-Australian Monsoon (AAM) system through overturning circulation linking the two hemispheres on seasonal time scale. The AAM precipitation domain is shown in Fig. 1.

Due to different land-ocean configuration and orography (especially the Tibetan plateau in the AAM domain), the Asian monsoons over Indian sector (west of 105E which marks the eastern periphery of the Tibetan Plateau) and

(a) July-August mean

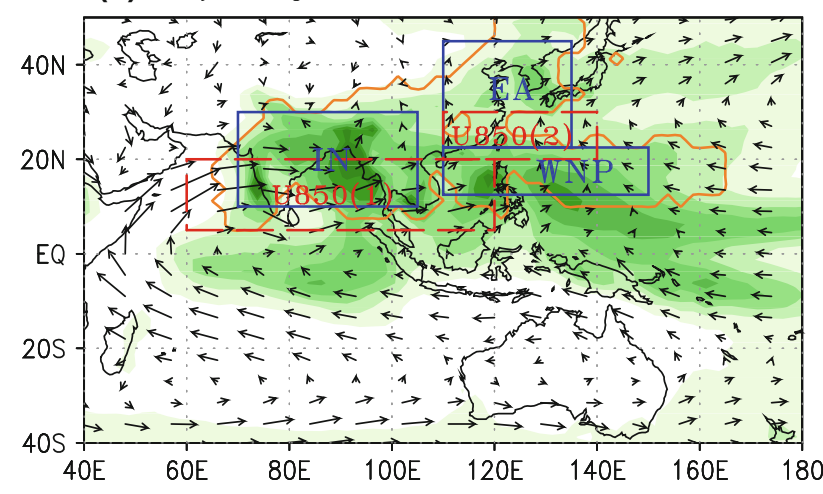

(b) January-February mean

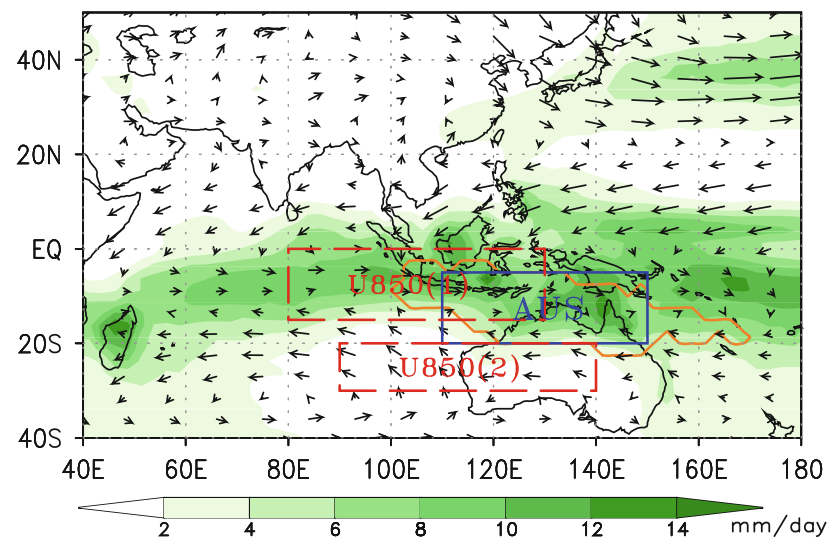

Fig. 1 The climatological mean fields of precipitation and low-level winds at $850 \mathrm{hPa}$ during (a) July-August and (b) January-February. The actual monsoon precipitation domain (orange) and the approximate regional monsoon boxes (blue) and the domain where the ASM and AusSM low-level circulation [U850(1) minus U850(2)] indices (red) are defined. The merged CMAP-GPCP data were used
East Asian (EA) sector (east of 105E) have distinctive features (Wang et al. 2001, 2003a). Over the EA sector, the summer monsoon is driven by both the north-south thermal contrast between cold Australian land and warmer WNP and the east-west thermal contrast between the heated EA landmass and relatively cold Pacific Ocean. This directionally 'orthogonal' forcing results in (a) a tropical monsoon in the WNP with a titled monsoon trough from the northern South China Sea to western Pacific $\left(5^{\circ} \mathrm{N}, 160^{\circ} \mathrm{E}\right)$, and (b) a subtropical monsoon consisting of WNP subtropical ridge and the EA subtropical rain belt. The terms 'Meiyu', 'Baiu', and 'Changma' are all associated with the same EA subtropical rain band that brings a major summer rainy period to the EA countries. Thus, the Asian monsoon can be divided into three subsystems: Indian, EA and WNP (Fig. 1).

The monsoon interannual variations have been studied primarily on regional scales, including the Indian monsoon (e.g., Mooley and Parthasarathy 1984; Shukla 1987), the Indonesian-Australian monsoon (e.g., Yasunari and Suppiah 1988; Hamada et al. 2002), the EA monsoon (e.g., Nitta 1987; Huang and Wu 1989; Zhou and Yu 2005), and the WNP monsoon (Wu and Wang 2000). The linkages among various regional monsoons are also recognized such as Indian and Australian monsoons (e.g., Meehl 1987), WNP and EA summer monsoons (e.g., Nitta 1987; Lau 1992; Ding 1994; Ha et al. 2012; Wang et al. 2013), the Indian and EA summer monsoons (e.g., Liang 1988; Guo and Wang 1988; Kripalani and Singh 1993; Enomoto et al. 2003; Ding and Wang 2005; Lee et al. 2011) and the EA and Australian monsoon (e.g., Wang et al. 2003a). The year-to-year variations in the vast AAM domain exhibit remarkable regional differences and depend strongly on the seasonal March and evolution of El Nino-Southern Oscillation (ENSO) (e.g., Wang et al. 2008b).

To describe the season-dependent evolution and the linkage among regional monsoons and to identify the major mode of interannual variability of the entire AAM system, Wang et al. (2003b), for the first time, introduced a season-reliant singular vector decomposition (SVD) analysis (SVD is also known as Maximum Covariance Analysis, or MCA) approach to describe the seasonally evolving patterns of the AAM anomalies associated with the ENSO evolution. The leading mode they found is essentially the same as the leading seasonreliant empirical orthogonal function (EOF) mode of the AAM precipitation anomalies alone (Wang et al. 2008a), indicating the robustness of this mode. This leading mode of variability of the AAM system will be used to facilitate detection of future change of the interannual variation of the AAM and ENSO-AAM relationship, which is critical for understanding future climate of the AAM predictability.

For the future change of the AAM system, the Intergovernmental Panel on Climate Change (IPCC) Fourth 
assessment report (AR4) stated that the current understanding of future climate change in the monsoon regions remains one of considerable uncertainty with respect to circulation and precipitation (IPCC AR4 Sections 3.7, 8.4.10 and 10.3.5.2). Increasing precipitation (along with an increase in interannual season-averaged precipitation variability) was projected to occur in the Asian and the Australian summer monsoon in a warmer climate (Meehl et al. 2007; Kripalani et al. 2007a, b; Sun et al. 2010). Differently from precipitation, Asian monsoon circulation was projected to decrease by $15 \%$ (Tanaka et al. 2005; Ueda et al. 2006). However, the uncertain role of aerosols complicates the nature of future projections of monsoon precipitation, particularly in the Asian monsoon.

The present study assesses future changes of AAM system in the domain of $40^{\circ} \mathrm{S}-50^{\circ} \mathrm{N}, 40^{\circ}-180^{\circ} \mathrm{E}$ using 20 CGCMs that participated in the phase five of the Coupled Model Intercomparison Project (CMIP5). Particular attention is paid to model selections and understanding the reasons behind those changes in terms of fundamental monsoon dynamics. We primarily compare two runs: the historical run under changing solar-volcanic forcing and anthropogenic influences from 1850 to 2005 and the RCP 4.5 run in which the radiative forcing is assumed to stabilize at a level about $4.5 \mathrm{Wm}^{-2}$ after 2100 (Taylor et al. 2012).

The model and data are described in Sect. 2. In Sect. 3, we evaluate historical simulations of 20 CGCMs against the observation for the period of 1980 to 2005 and select best models for making a multi-model mean (MMM). Section 4 is the major body of this work, focusing on the future changes of AAM. Section 5 discusses possible factors that are responsible for the AAM changes. The last section presents a summary.

\section{Model and data}

\subsection{Models and CMIP 5 experiments}

The succinct information about the 20 CMIP5 CGCMs used in this study is listed in Table 1. Two experiments are investigated. The historical run from 1850 to 2005 was forced by imposed changing conditions consistent with observations which include (but not necessarily all of the following) atmospheric composition (including $\mathrm{CO}_{2}$ ) due to both anthropogenic and volcanic influences, solar forcing, emissions or concentrations of short-lived species and natural and anthropogenic aerosols or their precursors, and land use. The RCP 4.5 run from 2006 to 2100 assumes that radiative forcing will stabilize at a level about $4.5 \mathrm{Wm}^{-2}$ after 2100 and is chosen as a "central" scenario in CMIP5 (Taylor et al. 2012). In general, the CMIP5 CGCMs have a larger number of ensemble simulations for the historical run than for the RCP 4.5 run. For a fair comparison, we used the same number of ensemble members in individual models for the two runs. Table 1 shows the number of ensemble members used for each model. The multi-model mean (MMM) was constructed with an equal weight.

\subsection{Observations}

Monthly precipitation data used in this study were obtained from (1) the Climate Prediction Center (CPC) Merged Analysis of Precipitation (CMAP) dataset (Xie and Arkin 1997) from 1979 to 2010, (2) Global Precipitation Climatology Project (GPCP) data version 2.2 from 1979 to 2010 (Huffman et al. 2011), and (3) merged statistical analyses of historical monthly precipitation anomalies (20C RECG) from 1900 to 2008 (Smith et al. 2010). The Twentieth Century Reanalysis (20CR) data (Compo et al. 2011) were used for monthly surface air temperature, mean sea level pressure, horizontal winds, and air temperature from 1871 to 2010. For validation of precipitation and SST, CMAP and GPCP precipitation dataset and the National Oceanic Atmospheric Administration (NOAA) extended reconstructed SST (ERSST) version 3 (Smith et al. 2008) data were used.

To validate the CGCMs in their historical simulations with respect to observation, all observed data and each model's output were interpolated to a common $2.5^{\circ}$ lat. $\times$ $2.5^{\circ}$ lon. grid. Both the observed and model simulated climatology were obtained for the 26-year period of 1980 to 2005 .

\section{Evaluation of CMIP5 models' performance and selection of the best models}

The evaluation metrics used to assess models' performance in simulation of the AAM precipitation climatology includes (1) the annual mean precipitation, (2) the first and second annual cycle modes of annual variation of precipitation (i.e. the solstice mode and equinox asymmetric mode), (3) monsoon precipitation intensity and domain. One can find the detail information on the metrics in Wang and Ding (2008) and Wang et al. (2011). Recently, Lee and Wang (2012) evaluated the CMIP5 models in simulating the precipitation climatology for the global monsoon. This paper focuses on AAM climatology and variability.

To evaluate models' performance in simulation of AAM interannual variation, we analyze the leading season-reliant EOF (S-EOF) mode of the AAM precipitation and associated Pacific SST anomalies for the 26-year period (1980-2005). The evaluation was made for each individual model. Based on models' performance in simulating not only the AAM precipitation climatology but also the 
Table 1 Description of participating models in CMIP5

\begin{tabular}{|c|c|c|c|c|}
\hline $\begin{array}{l}\text { Model } \\
\text { no }\end{array}$ & $\begin{array}{l}\text { Coupled } \\
\text { model }\end{array}$ & Institution & $\begin{array}{l}\text { AGCM } \\
\text { resolution }\end{array}$ & Ens no \\
\hline 1 & ACCESS1-0 & $\begin{array}{l}\text { Commonwealth Scientific and Industrial Research Organisation } \\
\text { and Bureau of Meteorology, Australia (CSIRO-BOM) }\end{array}$ & $1.875^{\circ} \times 1.25^{\circ}$ & 1 \\
\hline 2 & BCC-CSM1.1 & Beijing Climate Center, China Meteorological Administration (BCC) & $2.8125^{\circ} \times 2.8125^{\circ}$ & 1 \\
\hline 3 & CanESM2 & Canadian Centre for Climate Modelling and Analysis (CCCma) & $2.8125^{\circ} \times 2.8125^{\circ}$ & 5 \\
\hline 4 & CCSM4 & National Center for Atmospheric Research (NCAR) & $1.25^{\circ} \times 0.9375^{\circ}$ & 1 \\
\hline 5 & CNRM-CM5 & $\begin{array}{l}\text { Centre National de Recherches Meteorologiques/Centre Europeen de } \\
\text { Recherche et Formation Avancees en Calcul Scientifique (CNRM-CERFACS) }\end{array}$ & $1.40625^{\circ} \times 11.40625^{\circ}$ & 1 \\
\hline 6 & CSIRO-Mk3-6-0 & $\begin{array}{l}\text { Commonwealth Scientific and Industrial Research Organisation } \\
\text { and the Queensland Climate Change Centre of Excellence (CSIRO-QCCCE) }\end{array}$ & $1.875^{\circ} \times 1.875^{\circ}$ & 3 \\
\hline 7 & FGOALS-g2 & $\begin{array}{l}\text { LASG, Institute of Atmospheric Physics, Chinease Academy } \\
\text { of Sciences; and CESS, Tsinghua University (LASG-CESS) }\end{array}$ & $2.8125^{\circ} \times 2.8125^{\circ}$ & 1 \\
\hline 8 & GFDL-CM3 & Geophysical Fluid Dynamics Laboratory & $2.5^{\circ} \times 2^{\circ}$ & 1 \\
\hline 9 & GFDL-ESM2 M & (NOAA GFDL) & $2.5^{\circ} \times 2^{\circ}$ & 1 \\
\hline 10 & GISS-E2-R & NASA Goddard Institute for Space Studies (NASA GISS) & $2.5^{\circ} \times 2^{\circ}$ & 2 \\
\hline 11 & HadGEM2-CC & Met Office Hadley Centre (MOHC) & $1.875^{\circ} \times 1.24^{\circ}$ & 1 \\
\hline 12 & HadGEM2-ES & & $1.875^{\circ} \times 1.24^{\circ}$ & 1 \\
\hline 13 & INM-CM4 & Institute for Numerical Mathematics (INM) & $2^{\circ} \times 1.5^{\circ}$ & 1 \\
\hline 14 & IPSL-CM5A-LR & Institute Pierre-Simon Laplace (IPSL) & $3.75^{\circ} \times 1.875^{\circ}$ & 4 \\
\hline 15 & IPSL-CM5A-MR & & $2.5^{\circ} \times 1.258^{\circ}$ & \\
\hline 16 & MIROC5 & Atmosphere and Ocean Research Institute (University of Tokyo), & $1.40625^{\circ} \times 1.40625^{\circ}$ & 1 \\
\hline 17 & MIROC-ESM & $\begin{array}{l}\text { National Institute for Environmental Studies, and Japan Agency } \\
\text { for Marine-Earth Science and Technology (MIROC) }\end{array}$ & $2.8125^{\circ} \times 2.8125^{\circ}$ & 1 \\
\hline 18 & MPI-ESM-LR & Max Planck Institute for Meteorology (MPI-M) & $1.875^{\circ} \times 1.875^{\circ}$ & 3 \\
\hline 19 & MRI-CGCM3 & Meteorological Research Institute (MRI) & $1.125^{\circ} \times 2.25^{\circ}$ & 1 \\
\hline 20 & NorESM1-M & Norwegian Climate Centre (NCC) & $2.5^{\circ} \times 1.875^{\circ}$ & 1 \\
\hline
\end{tabular}

leading S-EOF mode of AAM variability, we select the best seven models for further analyses of the AAM future change. In the following subsections, we will show evaluation results in individual models and their MMM together with the best seven models' MMM (B7MMM hereafter). Section 3.5 will discuss how to select the best models in detail.

\subsection{Annual mean precipitation}

The 20 CGCMs' MMM realistically reproduces the observed features of annual mean precipitation over the AAM region (Fig. 2). A difference map (not shown) indicates that the MMM tends to underestimate precipitation over the Eastern Indian Ocean, the Bay of Bengal, and East Asia, but overestimate precipitation over the Maritime Continent, Philippines, and the Tibetan Plateau. These biases are common in the state-of-the-art coupled models (Lee et al. 2010; Lee and Wang 2012). To objectively evaluate the models' performance, we calculate the pattern correlation coefficient (PCC) between the observation and simulation over the AAM region of $40^{\circ} \mathrm{S}-50^{\circ} \mathrm{N}, 40^{\circ}-$ $180^{\circ} \mathrm{E}$. The all model's MMM has the PCC of 0.93 .
Figure 2 also shows the simulated annual mean precipitation by the selected B7MMM. As mentioned, how to select the best models will be explained in Sect. 3.5. Basically, the B7MMM has very similar distribution in annual mean precipitation with the all models' MMM, having the PCC skill of 0.94. The major difference between them is the signal-to-noise ratio. The signal is measured by the amplitude of MMM and the noise is estimated by the standard deviation of inter-model spread against the MMM. If the number of models being used increases, the signal-to-noise ratio tends to decrease and thus the level of uncertainty in the MMM simulation increases. The singleto-noise ratio for the B7MMM in simulating long-term annual mean precipitation is 5.5 averaged over the AAM region, but that for the all models' $\mathrm{MMM}$ is 4.4.

Figure 3 a compares the PCC and normalized root mean square error (NRMSE) between the observation and simulation by each individual CGCMs and their MMM over the AAM region. The NRMSE is the RMSE normalized by the observed mean standard deviation that is calculated with reference to the AAM area. The individual models' PCCs range from 0.77 to 0.92 and NRMSE ranges from 0.42 to 0.83 (Fig. 3a). The MMM and B7MMM are 
evidently better than any individual models in simulating annual mean precipitation with the PCC of 0.93 and 0.94 , respectively, and the NRMSE of 0.37 and 0.35 , respectively.

\subsection{The first and second modes of annual variation}

The first annual cycle mode (the solstice mode) can be captured extremely well by the difference between JuneJuly-August-September (JJAS) and December-JanuaryFebruary-March (DJFM) mean precipitation (Wang and Ding 2008). The second mode (the equinox asymmetric mode or spring-fall asymmetric mode) can be very well described by the difference between April-May (AM) and October-November $(\mathrm{ON})$ mean precipitation. Figure $2 b$ shows that the 20 models' MMM reproduces the solstice mode with a high fidelity $(\mathrm{PCC}=0.92)$ and the equinox asymmetric mode reasonably realistic $(\mathrm{PCC}=0.76)$. The models tend to underestimate the solstice mode over the East Asia, the South China Sea and Philippine Sea and overestimate the equinox mode over most of the AAM region. With quantitative measures, the CMIP5 models can reproduce the observed solstice mode realistically with PCCs ranging from 0.74 to 0.88 and NRMSEs from 0.48 to 0.94 (Fig. 3b). However, the models have difficulties in (a) Observation

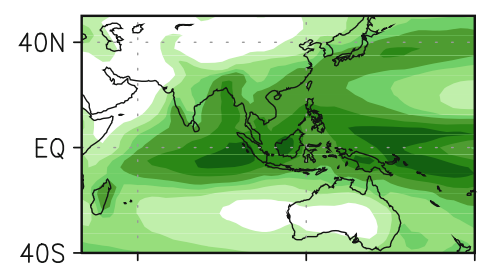

(b) 20 Models' MMM

Annual mean precipitation rate (c) $\mathrm{B} 7 \mathrm{MMM}$

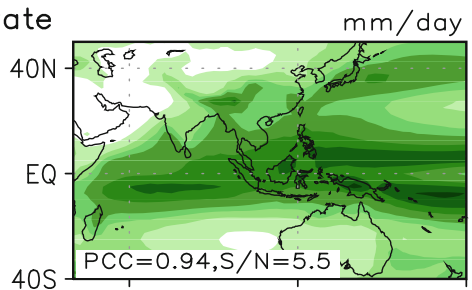

The first annual cycle of precipitation rate
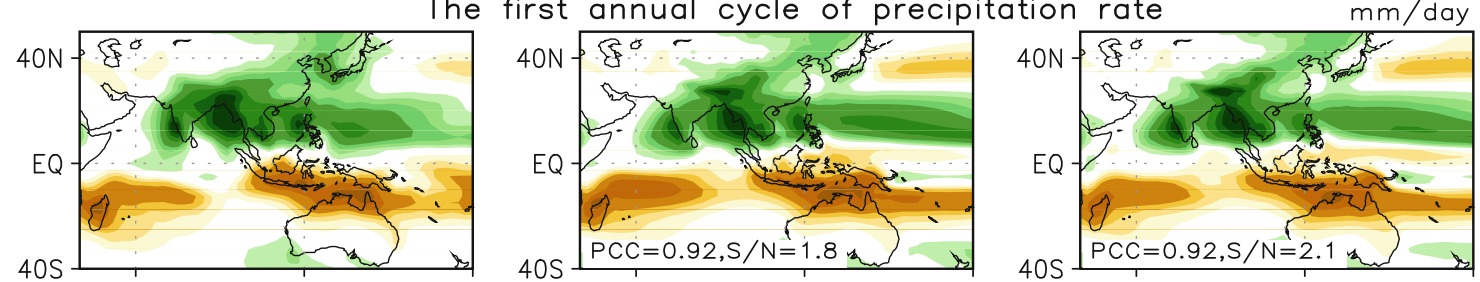

The second annual cycle of precipitation rate
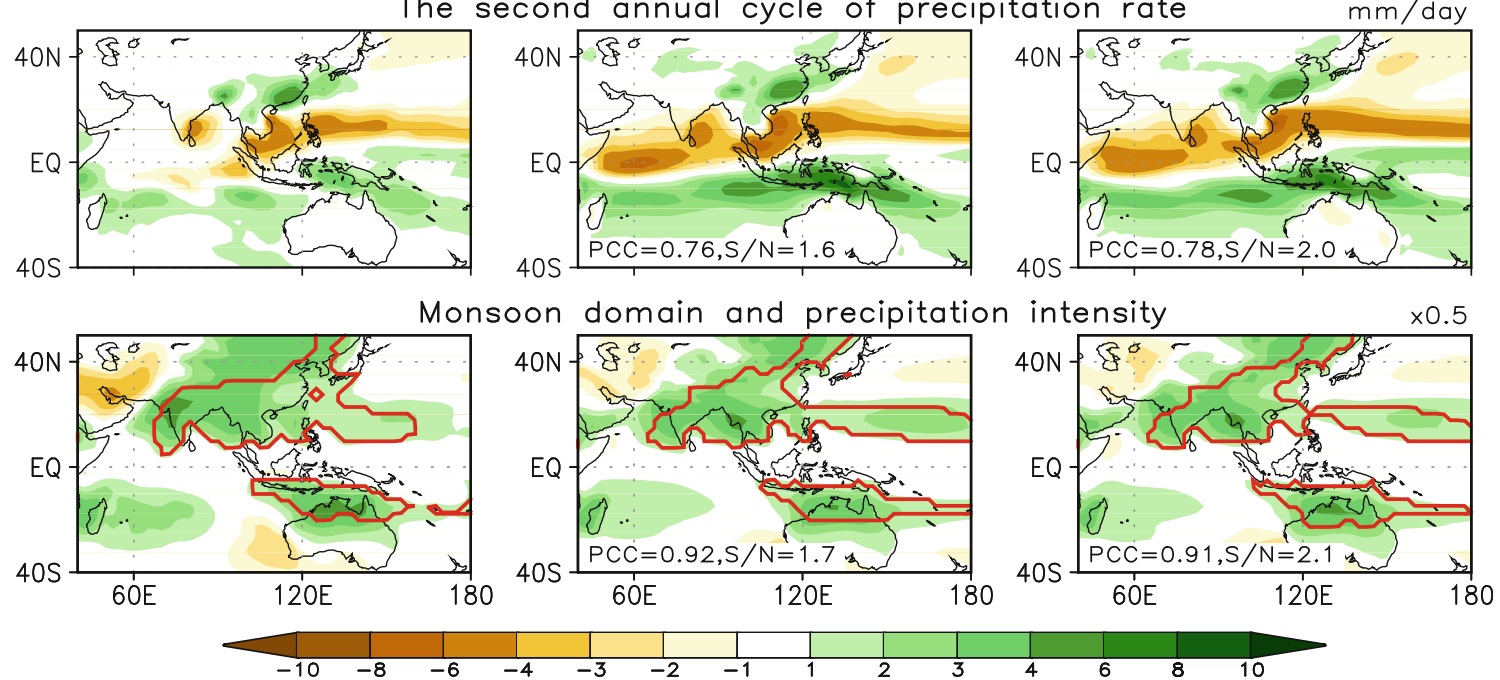

Fig. 2 Comparison of (a) the observed (merged CMAP and GPCP) and the simulated monsoon climatology by (b) 20 models' multimodel mean (MMM) and (c) the best seven models' MMM (B7MMM) for 1980-2005 in terms of annual mean precipitation rate (mm/day), the first annual cycle mode (solstice mode, JJAS minus DJFM), the second annual cycle mode (equinoctial asymmetric mode, $\mathrm{AM}$ minus $\mathrm{ON}$ ), and monsoon domain and monsoon precipitation intensity (non dimensional and need to multiply 0.5 for original value). The observed monsoon precipitation domain (outlined by red contours) is defined by the regions where the summer-minus-winter precipitation exceeds $2.5 \mathrm{~mm} /$ day and the summer precipitation exceeds $55 \%$ of the annual total, where summer means MJJAS (NDJFM) for the $\mathrm{NH}(\mathrm{SH})$. The numbers in the right lower corners indicate pattern correlation coefficient (PCC) between the observed and simulated patterns and signal to noise ratio $(\mathrm{S} / \mathrm{N})$ measuring MMM's amplitude relative to inter-model spread over the AAM domain 
(a) AM

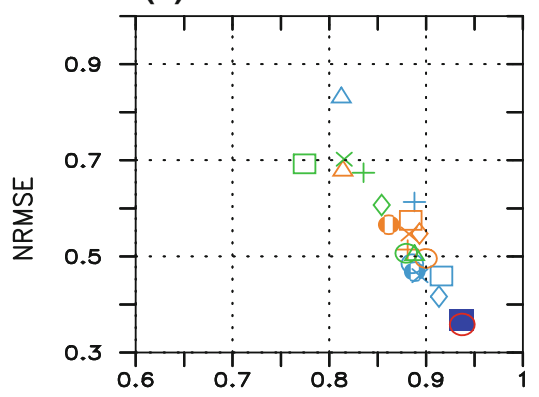

(b) AC1

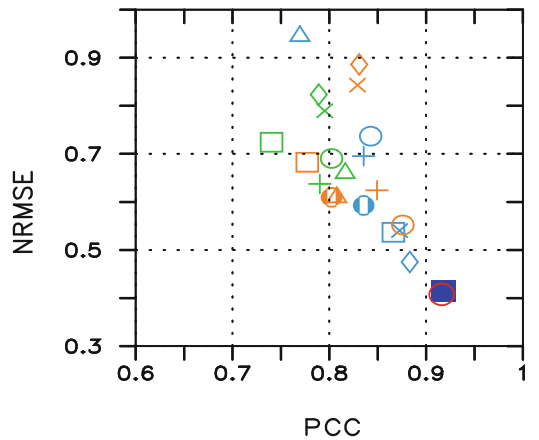

(c) $\mathrm{AC2}$

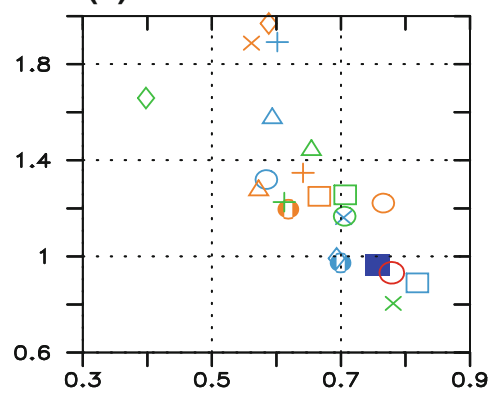

(d) MPI

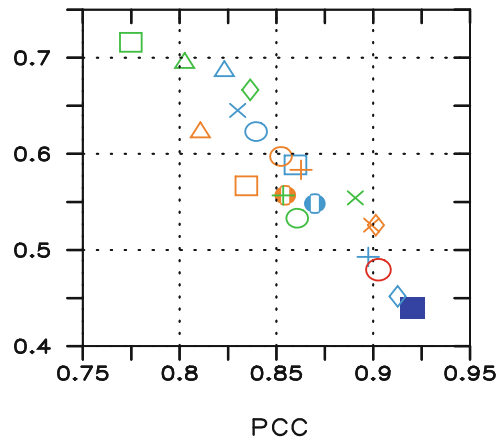

\begin{tabular}{|c|c|c|c|c|c|c|}
\hline MMM & О В7мММ & & & & & \\
\hline + ACCESS1 & BCC-CSM 1 & $\square$ CanESM2 & $\times \operatorname{ccs} 44$ & $\diamond \mathrm{CNRM}-\mathrm{CM} 5$ & $\triangle \mathrm{CSIRO}-\mathrm{MK} 3$ & O FGOALS-g2 \\
\hline + GFDL-CM3 & GFDL-ESM2M & $\square$ GISS-E2 & $\times \operatorname{HadGEM} 2-\mathrm{CC}$ & $\diamond$ HadGEM2-ES & $\triangle \mathrm{INMCM4}$ & O IPSL-LR \\
\hline+ IPSL-MR & MIROC5 & $\square$ MIROC-ESM & $\times$ MPI-ESM & $\diamond \mathrm{MRI}-\mathrm{CGCM} 3$ & $\triangle$ NorESM1-M & \\
\hline
\end{tabular}

Fig. 3 Model's performance on simulation of the AAM precipitation climatology (1980-2005): (a) annual mean precipitation, (b) the solstice mode (AC1, JJAS minus DJFM), (c) the equinoctial asymmetric mode (AC2, AM minus $\mathrm{ON}$ ), and (d) monsoon precipitation intensity (MPI) over the AAM region. The abscissa and

simulating the equinox mode with substantially larger NRMSEs from 0.8 to 2.0 and lower PCCs from 0.37 to 0.73 (Fig. 3c). The MMM is more effective for the solstice mode than the equinox mode, since a number of models' perform poorly on the equinox mode. Figure $3 \mathrm{c}$ also shows that the two best models, the CanESM2 and MPI-ESM, have even better skills than the all model MMM. The B7MMM has slightly better skills for the both annual cycle modes with larger signal-to-noise ratio than the 20 models' MMM.

\subsection{The monsoon precipitation intensity and domain}

The monsoon precipitation (MP) intensity is defined by the ratio of local summer-minus-winter precipitation to the annual total, where summer refers to May-June-JulyAugust-September (MJJAS) for the NH and NovemberDecember-January-February-March (NDJFM) for the SH. For the AAM system, the MP intensity is area-averaged MP intensity in the observed MP domain. Note that each model has different MP domain but the MP intensity is calculated for the same observed domain. The MP domain ordinates are pattern correlation coefficient (PCC) and domainaveraged RMSE normalized by the observed spatial standard deviation (NRMSE), respectively. The domain used is $40^{\circ} \mathrm{S}-50^{\circ} \mathrm{N}$, $40^{\circ}-180^{\circ} \mathrm{E}$

is defined by the regions where the summer-minus-winter precipitation exceeds $2.5 \mathrm{~mm}^{-1}$ day $^{-1}$ and the MP intensity exceeds 0.55 (Wang et al. 2011). The CMIP5 20 models' MMM well captures the MP intensity but only to some extent, the MP domain over the AAM region (Fig. 2b). The EA monsoon precipitation intensity is underestimated. A large part of the monsoon domain over the subtropical EA is missed while over the WNP is extended too far into the central Pacific. The PCC and NRMSE between the observed and simulated AAM precipitation intensity range from 0.78 to 0.92 and from 0.45 to 0.72 , respectively (Fig. 3d). The 20-model MMM has the PCC of 0.92 and the RMSE of 0.44. It is also shown that the all models' MMM has slightly better skill for the MP intensity and domain than the B7MMM, But it has less signal-to-noise ratio (1.7 for MMM and 2.1 for B7MMM) for the simulation of MP intensity.

\subsection{Evaluation of the leading mode of AAM}

The S-EOF was applied to evaluate all models' performance in simulating the leading mode of interannual 
precipitation variability over the AAM region $\left(60^{\circ} \mathrm{E}-\right.$ $160^{\circ} \mathrm{E}, 30^{\circ} \mathrm{S}-40^{\circ} \mathrm{N}$ ) with consecutive four seasons for the period 1980-2005. The seasonal sequence for precipitation is $\operatorname{JJA}($ year 0 ), $\operatorname{SON}(0), \mathrm{D}(0) \mathrm{JF}$ (year 1), and MAM(1). The Pacific SST anomalies $\left(120^{\circ} \mathrm{E}-70^{\circ} \mathrm{W}, 30^{\circ} \mathrm{S}-30^{\circ} \mathrm{N}\right)$ during $\mathrm{D}(0) \mathrm{JF}(1)$ associated with the leading AAM mode in all models are also investigated.

Figure 4 shows the spatial distribution of precipitation with seasonal sequences and the regressed DJF SST for the observed and simulated leading mode of AAM interannual variation. The observed leading mode (Fig. 4a) is associated with the turnabout of warming to cooling in the ENSO with a strong biennial tendency (Wang et al. 2008b). In $\mathrm{JJA}(0)$, the large-scale suppressed convections are located over the maritime continent and the equatorial eastern Indian Ocean while enhanced rainfall is found over the equatorial western Pacific extended northward to the Philippine Sea and the Bay of Bengal. During SON(0), the dry anomalies over the maritime continent intensify and expand northward and eastward, covering the Philippine archipelago and the entire tropical South Asia and northern Australia. From the SON to the DJF season, the entire anomalies move slowly eastward with the most suppressed convection shifting to the Philippine Sea. From DJF to the next MAM, the dry anomalies decay rapidly and move further eastward with a dry center occurring in the equatorial western Pacific. Figure $4 \mathrm{~b}$ indicates that the B7MMM is capable of capturing the observed precipitation evolution associated with the ENSO turnabout in general. The PCC between the observed and simulated DJF SST anomalies is 0.95 and the PCCs for the seasonal precipitation are $0.83,0.61,0.53$ and 0.69 , respectively from $\mathrm{JJA}(0)$ to $\mathrm{MAM}(1)$.

Figure 5 compares the individual models' performances on simulation of the leading AAM mode and ENSO, in terms of simulated precipitation and SST spatial patterns measured by the PCC. The PCCs vary tremendously from model to model. The SST patterns are captured a lot better than the precipitation patterns in general. The reasons for poor simulations of the monsoon precipitation are arguably due to models' deficiencies in simulation of tropical ENSO teleconnection and monsoon-warm pool ocean interaction.

\subsection{Selection of best models}

Taking into account the significant inter-model spread over their MMM, particularly for the second annual cycle modes shown in Fig. 3c and the leading mode of AAM variability shown in Fig. 5, we select the best models in reproducing the AAM precipitation climatology and variability in order to get more reliable MMM for construction and future projection. The model selection is based on the PCC for climatology and interannual variability, and the signal-tonoise ratio measures for climatology. We define the combined PCC skill using the PCC for annual mean precipitation $\left(\mathrm{PCC}_{\mathrm{AM}}\right)$, the weighted first and second annual cycle $\left(\mathrm{PCC}_{\mathrm{AC} 1}\right.$ and $\left.\mathrm{PCC}_{\mathrm{AC} 2}\right)$, the MP intensity $\left(\mathrm{PCC}_{\mathrm{MPI}}\right)$, and seasonal sequences of precipitation and associated SST for the leading S-EOF mode ( $\mathrm{PCC}_{\text {SEOFJJA }}$ PCC $\mathrm{PCOFSON}_{\text {SES }}$ $\mathrm{PCC}_{\text {SEOFDJF, }}$, and $\mathrm{PCC}_{\text {SEOFMAM }}, \mathrm{PCC}_{\text {SSTReg }}$, respectively) as follows:

$$
\begin{aligned}
\text { Skill }_{\text {com }}= & \frac{0.5}{3} \times\left(P C C_{A M}+\frac{\lambda_{1}}{\lambda_{1}+\lambda_{2}} P C C_{A C 1}\right. \\
& \left.+\frac{\lambda_{2}}{\lambda_{1}+\lambda_{2}} P C C_{A C 2}+P C C_{M P I}\right)+\frac{0.5}{5} \\
& \times\left(P C C_{\text {SEOFJIA }}+P C C_{\text {SEOFSON }}+P C C_{\text {SEOFDJF }}\right. \\
& \left.+P C C_{\text {SEOFMAM }}+P C C_{\text {SSTReg }}\right)
\end{aligned}
$$

The PCC skills for the first and second annual cycle mode are weighted by their observed fractional-variance contributions to the annual variation, where the observed first eigenvalue $\left(\lambda_{1}\right)$ is 0.68 and the second $\left(\lambda_{2}\right)$ is 0.17 .

Figure 6a shows the combined PCC skill as a function of models in a decreasing order. Refer Table 1 for the model number. The best model is CNRM-CM5 taking into account all measures for AAM climatology and variability. The signal-to-noise ratio is defined by the ratio of the absolute value of the MMM (as a signal) to inter-model standard deviation against the MMM (as a noise). We take a mean of the signal-to-noise ratio for annual mean precipitation, the first two annual cycle modes weighted by their observed fractional-variance contributions to the annual cycle, and the MP intensity as a function of the number of best models selected for MMM (Fig. 6b). In general, the signal-to-noise ratio decreases as the number of models being used increases. It is difficult to objectively select the number of best models for optimal result. In this study, we decide to use the seven best models that have the combined skill higher than 0.7 and the signal-to-noise ratio higher than 3.5. The best seven models selected are CNRM-CM5, CCSM4, GFDL-ESM2 M, FGOALS-g2, NorESM1-M, GISS-E2, and CanESM5.

Figure 7 summarizes individual models' performance in AAM climatology in comparison to all models' MME and B7MME. For comparison, assessment was also made for the 19 CMIP3 models and their MME. One can find detail information on the CMIP3 models used in this study in Lee and Wang (2012). It is shown that there are significant improvements from the CMIP3 to CMIP5 in the skill measures. In particular, the CMIP5 models and their MMM better simulate monsoon precipitation intensity and domain (Fig. 7b). Sperber et al. (2012) found that the CMIP5 23 
(a) Observation (24.2\%)
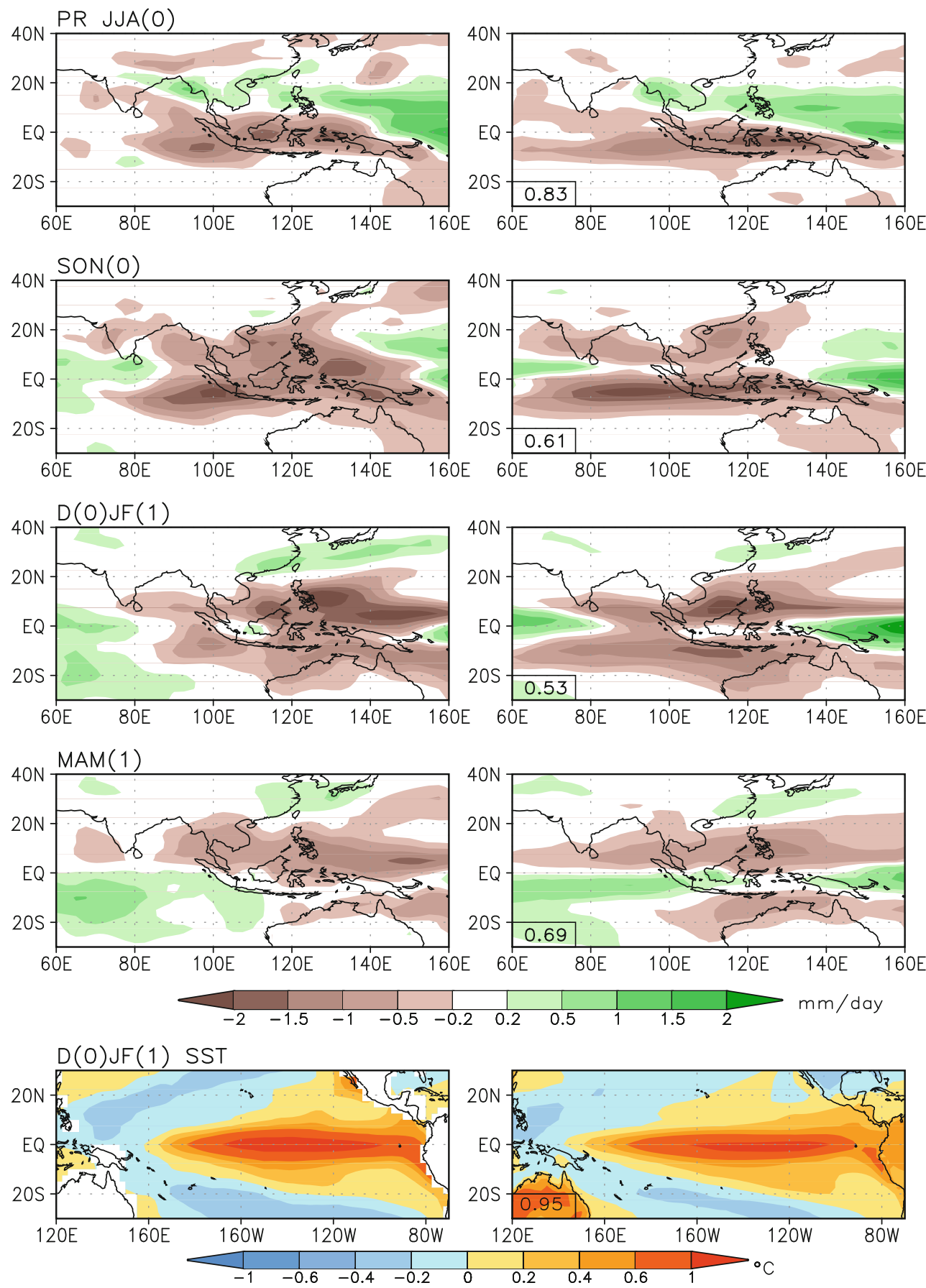

Fig. 4 The (a) observed and (b) simulated leading modes of seasonreliant EOF (S-EOF) of seasonal precipitation anomalies over AAM region $\left(60^{\circ} \mathrm{E}-180^{\circ} \mathrm{E}\right)$ and associated Pacific $\left(120^{\circ} \mathrm{E}-70^{\circ} \mathrm{W}\right.$ and $30^{\circ} \mathrm{S}-$ $30^{\circ} \mathrm{N}$ ) DJF SST anomalies for the present day (1980-2005), which explain about 24.2 and $26.7 \%$ of the total variance, respectively. The

models' MMM is more skillful than the CMIP3 MMM in many diagnostics in terms of the skill of simulating pattern correlations with respect to observations. But they did not (b) $B 7 M M M(26.7 \%)$
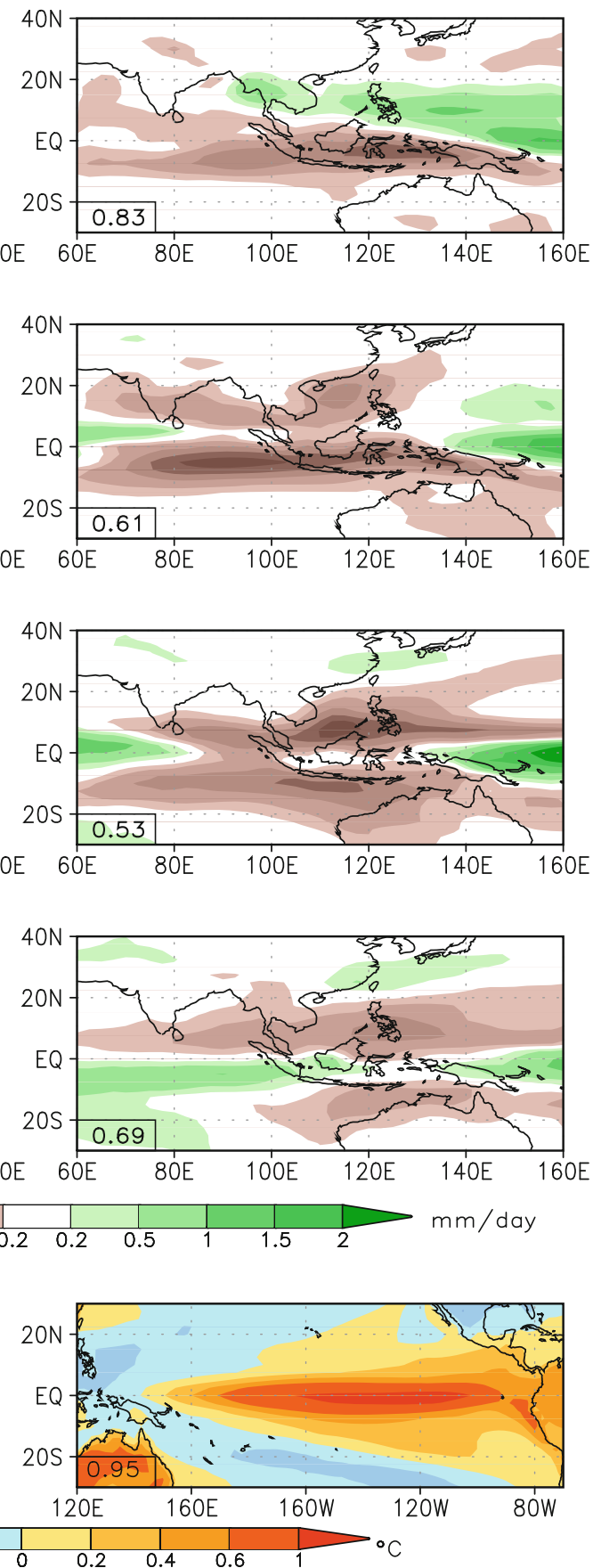

S-EOF analysis was applied to the best seven models (B7MMM) and the seasonal sequence is $\operatorname{JJA}(0), \operatorname{SON}(0), \mathrm{D}(0) \mathrm{JF}(1)$, and MAM(1). In (b), the number in the left lower corner indicates the pattern correlation coefficient (PCC) between the observed and the simulated spatial patterns

evaluate the monsoon precipitation intensity and domain. So the results here implemented Sperber et al (2012)'s evaluation. 


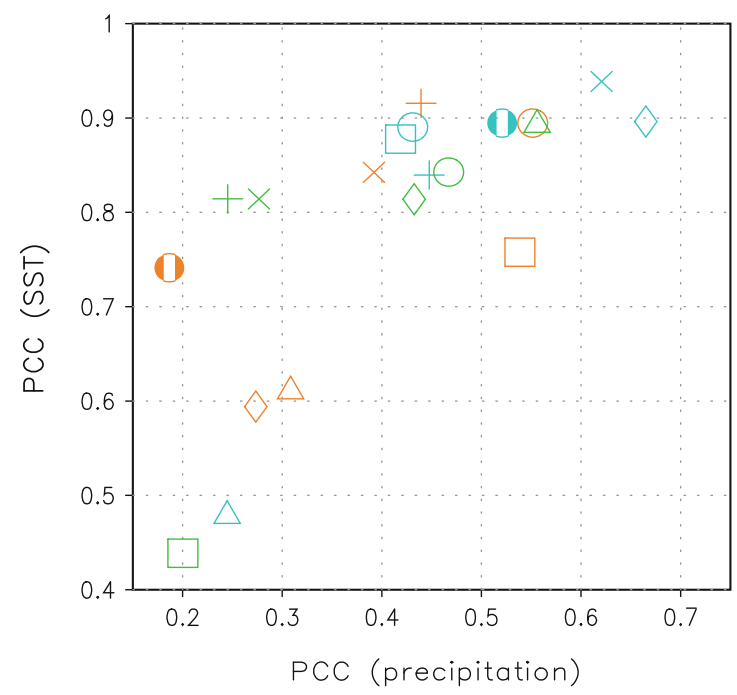

\begin{tabular}{|llllll|}
\hline+ ACCESS1 & OBCC-CSM1 & $\square$ CanESM2 & $\times$ CCSM4 & $\diamond$ CNRM-CM5 & $\triangle$ CSIRO-MK3 O FGOALS-g2 \\
+ GFDL-CM3 & $O$ GFDL-ESM2M & $\square$ GISS-E2 & $\times$ HadGEM2-CC & $\diamond$ HadGEM2-ES $\triangle$ INMCM4 & OIPSL-LR \\
+ IPSL-MR & $O M I R O C 5$ & $\square$ MIROC-ESM & $\times$ MPI-ESM & $\nabla$ MRI-CGCM3 $\triangle$ NorESM1-M
\end{tabular}

Fig. 5 Assessment of models' performance in simulating the leading S-EOF modes of precipitation and associated Pacific SST anomalies (1980-2005). The domains for precipitation and SST are $\left(60^{\circ} \mathrm{E}-\right.$ $\left.180^{\circ} \mathrm{E}, 30^{\circ} \mathrm{S}-40^{\circ} \mathrm{N}\right)$ and $\left(120^{\circ} \mathrm{E}-70^{\circ} \mathrm{W}, 30^{\circ} \mathrm{S}-30^{\circ} \mathrm{N}\right)$, respectively.

\section{Future change of AAM}

\subsection{Monsoon domain and monsoonality}

By comparing AAM precipitation climatology during the historical run period (1980-2005) and the RCP 4.5 run period (2070-2095) using the B7MMM along with the all models' MMM, we investigate the future change of monsoon domain and monsoonality. The monsoonality is defined by the ratio of local summer versus annual mean precipitation. Indian monsoon, for instance, has highest monsoonality, which reaches $80 \%$ or above.

Figure 8a compares the monsoon precipitation domain in the historical and RCP 4.5 run climatology. The B7MMM and all models' MMM project a $7.8 \%$ increase in the AAM domain in future that is less than the degree of inter-model spread (i.e. model uncertainty) and less than the MMM's bias over the observed domain, suggesting that this increase is not statistically significant. However, just over the Asian land area, the size of the monsoon domain will expand by about $10.0 \%$ (10.4 \%) using the B7MMM (all models' MMM) at the end of the $21^{\text {st }}$ century. Since the model's spread in the land monsoon boundary is relative small, this increase of land monsoon area is statistically significant.

The B7MMM predicts more significant change in monsoonality than the all models' MMM (lower panels in Fig. 8), particularly within the monsoon domain. Here the
The abscissa and ordinates are the season-averaged PCC for the precipitation and the PCC for DJF SST, respectively. The data used for observation is from the GPCP V2 (1980-2005) and ERSSTV3b

local summer refers to MJJAS (NDJFM) for the NH (SH). Stippling in Fig. 8 indicates area where the magnitude of the change in the monsoonality exceeds the uncertainty measured by standard deviation of inter-model changes. The proportion of local summer rainfall to annual mean precipitation will increase over Australian monsoon and subtropical Asian monsoon but drops in the southern edge of the Asian monsoon. This ratio tends to decrease over the Asian arid or semiarid region.

\subsection{Land and oceanic monsoon rainfall}

The AAM domain consists of both land and oceanic regions. To see how the monsoon precipitation will change in the land region and oceanic region separately, we have partitioned the total AAM precipitation into a land and an oceanic component. The results are shown in Fig. 9. First, for the present day (1980-2010), for which reliable global estimation of precipitation exists (for instance the GPCP data), the B7MMM captures the overall upward trends over both the land and ocean. The observed decadal variation cannot be reproduced because the MMM reduces the decadal variation arising from internal feedback processes. Result in Fig. 9 indicates that the land and oceanic monsoon rainfall in 21 st century have a comparable increasing trend. It is noted that the all models' MMM projects similar trends for both land and oceanic monsoon rainfall with larger uncertainty than the B7MMM (not shown). 
(a) The Combined Skill

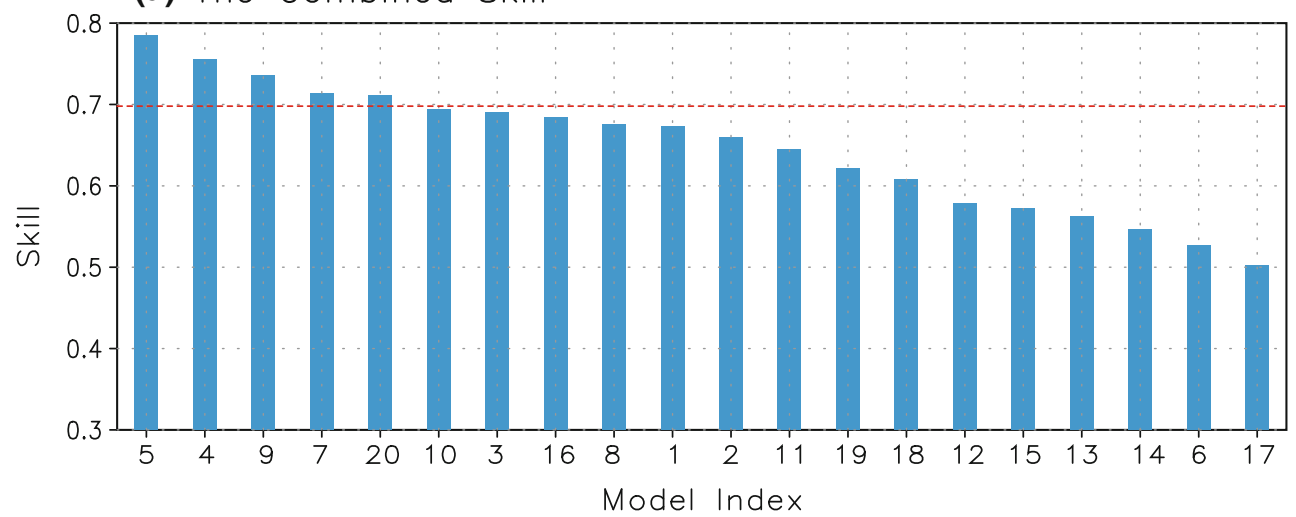

(b) The Combined Signal to Noise Ratio

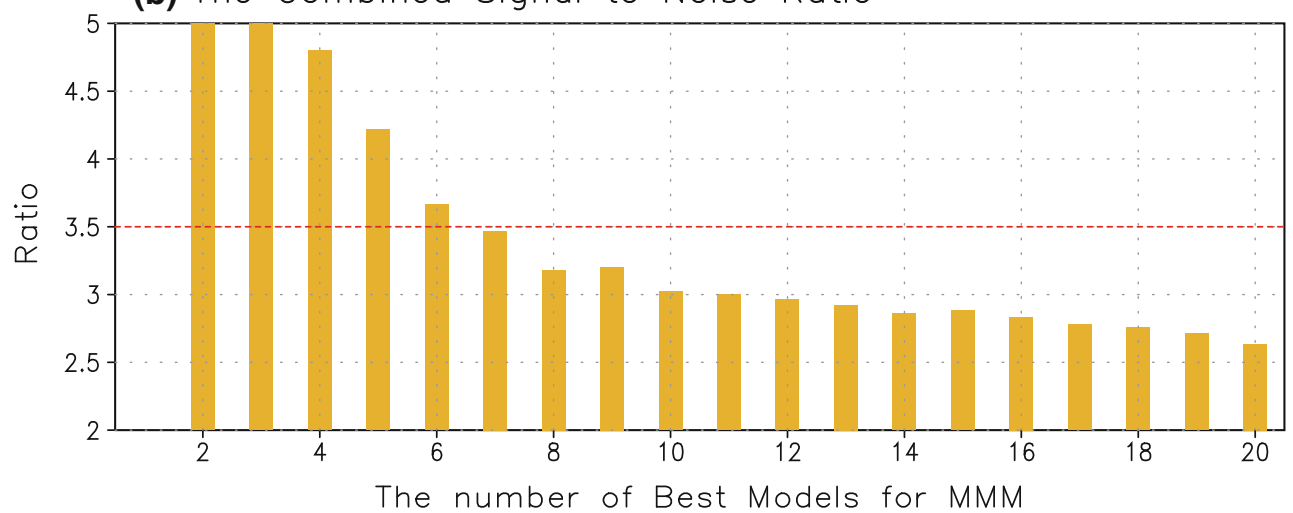

Fig. 6 a The combined PCC skill for AAM climatology and variability for individual models and (b) the averaged signal-to-noise ratio for annual mean precipitation, annual cycle, and monsoon precipitation intensity as a function of the number of selective best models being used for MMM. In (a) abscissa indicates model number shown in Table 1. The best seven models selected are CNRM-CM5, CCSM4, GFDL-ESM2M, FGOALS-g2, NorESM1-M, GISS-E2, and CanESM2 (a) $\mathrm{AM} \vee \mathrm{AC}$

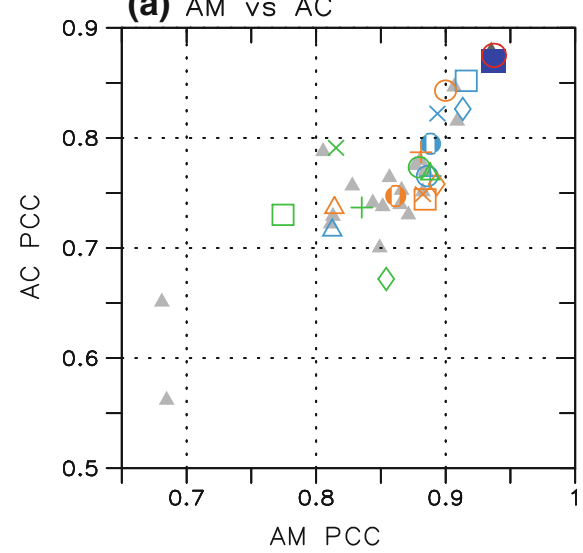

(b) A-A Monsoon

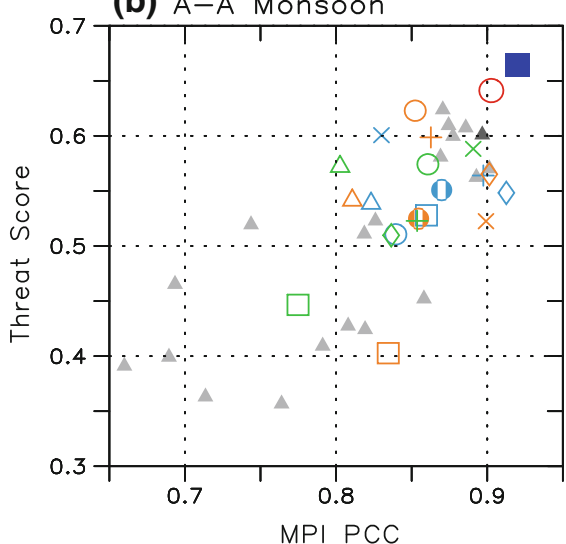

\begin{tabular}{|c|c|c|c|c|c|c|}
\hline MMM & В 7 MMM & $\triangle \mathrm{CMIP} 3-\mathrm{MMM}$ & $\triangle$ CMIP3-Individu & ual & & \\
\hline+ ACCESS1 & $\mathrm{BCC}-\mathrm{CSM} 1$ & $\square$ CanESM2 & $\times \operatorname{ccs} 44$ & $\diamond \mathrm{CNRM}-\mathrm{CM} 5$ & $\triangle \mathrm{CSIRO}-\mathrm{MK} 3$ & 0 FGOALS-g2 \\
\hline+ GFDL-CM3 & GFDL-ESM2M & $\square$ GISS-E2 & $\times \operatorname{HadGEM} 2-\mathrm{CC}$ & $\diamond$ HadGEM2-ES & $\triangle \mathrm{INMCM} 4$ & 0 IPSL-LR \\
\hline+ IPSL-MR & MIROC5 & $\square$ MIROC-ESM & $\times \mathrm{MPI}-\mathrm{ESM}$ & $\triangle \mathrm{MRI}-\mathrm{CGCM} 3$ & $\triangle$ NorESM $1-M$ & \\
\hline
\end{tabular}

Fig. 7 Overall assessment of the AAM simulation in 20 CGCMs, their MME, and the best seven models' MME: (a) PCCs of annual mean (abscissa) versus annual cycle (ordinate), and (b) PCC of the climatological MPI (abscissa) versus threat score of monsoon domain (ordinate). For comparison, assessment was also made for the 19 CMIP3 models and their MME 
(a) 20 Models' MMM

Monsoon rain domain
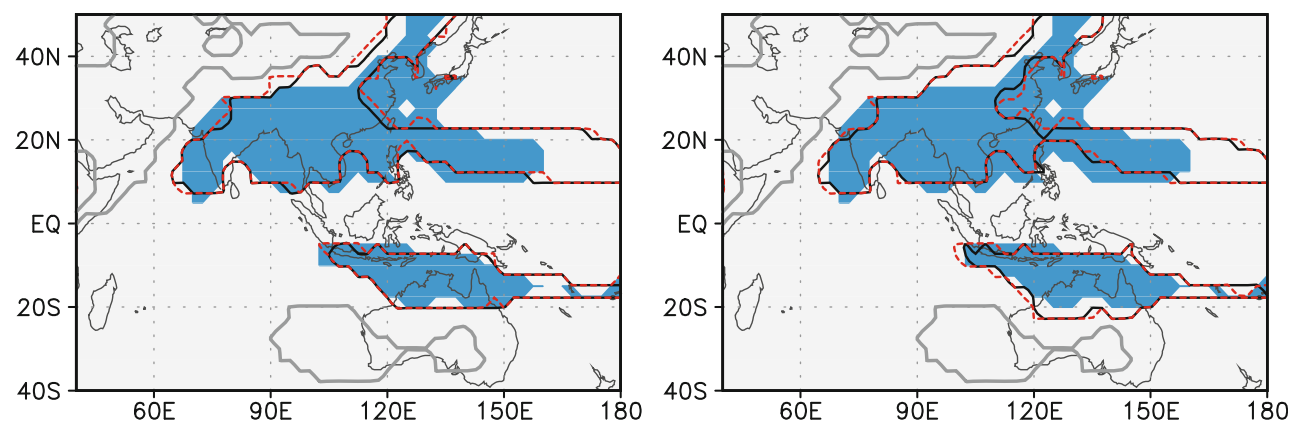

Percentage of local summer rainfall

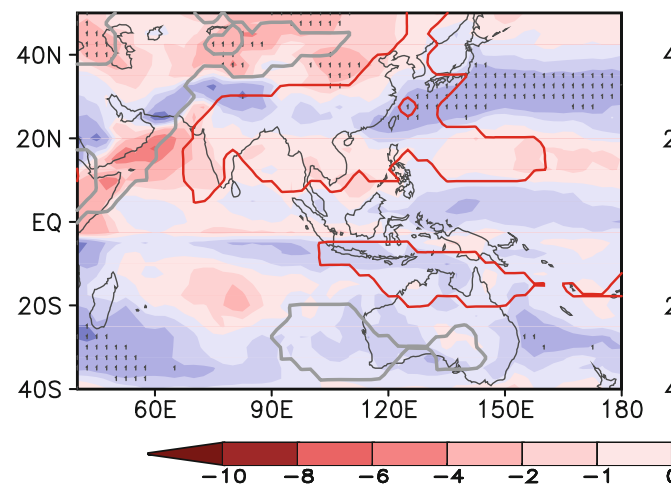

Fig. 8 Change of monsoon precipitation domain (upper panels) and percentage of local summer rainfall (lower panels) in the AAM region using (a) 20 models' MMM and (b) B7MMM. In upper panels, the monsoon domain is obtained from the observation (mid-blue shading), the historical simulation (black solid line), and RCP 4.5 simulation (red dashed line). The period used to determine the monsoon domain is from 1980 to 2005 for the observation and

\subsection{AAM precipitation and circulation intensity}

The precipitation and circulation intensities for the entire Asian summer monsoon (ASM) and the Australian summer monsoon (AusSM) are measured by the corresponding indices defined in the Table 2. The circulation index for the ASM quantifies the variation of the low-level circulation $(850 \mathrm{hPa})$, which is related to the corresponding ASM precipitation intensity index significantly with a correlation coefficient of 0.71 for the period of 1979-2010. This circulation index reflects not only the enhanced low-level southwesterly monsoon prevailing in South Asia $\left(5^{\circ}-20^{\circ} \mathrm{N}, 60^{\circ}-120^{\circ} \mathrm{E}\right)$, but also the enhanced subtropical southeasterlies associated with the WNP subtropical high in EA $\left(20^{\circ}-40^{\circ} \mathrm{N}, 120^{\circ} \mathrm{E}-140^{\circ} \mathrm{E}\right)$. The enhanced tropical southwesterlies signify strengthening of the tropical Indian summer monsoon (ISM) and WNP $\left(20^{\circ}-40^{\circ} \mathrm{N}, 120^{\circ} \mathrm{E}-140^{\circ} \mathrm{E}\right)$ summer monsoon (WNPSM); whereas the enhanced subtropical southeasterlies are a sign of strengthening EA summer monsoon (EASM). Figure 10 shows longterm trends of precipitation and (b) $B 7 \mathrm{MMM}$

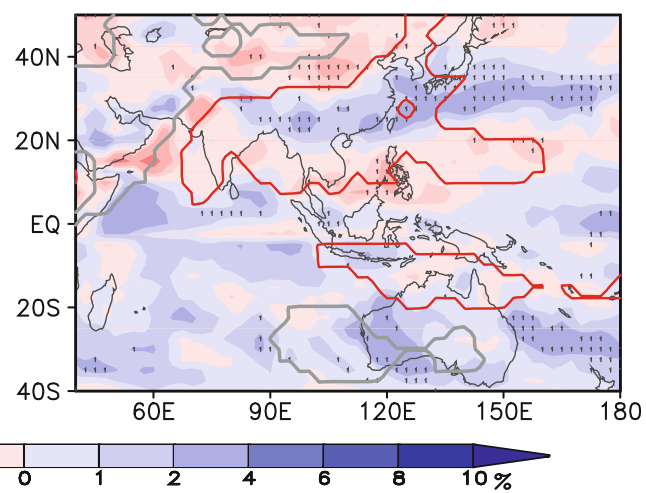

historically simulation and from 2070 to 2095 for the RCP 4.5 simulation. The definition of monsoon domain is the same as in Fig. 2 and the dry regions (outlined by grey) have summer precipitation rate $<1 \mathrm{~mm} /$ day. In low panels, (red solid line indicates the observed monsoon domain and stippling denotes areas where the magnitude of the B7MMM exceeds the inter-model standard deviation

circulation intensities in ASM and AusSM under the RCP 4.5 anthropogenic warming scenario relative to 1980-2005. The projection by B7MMM shows a significant increasing trend in ASM precipitation in $21^{\text {st }}$ century ( $4.5 \%$ increase given one degree warming); but a significant decreasing trend $(2.3 \%$ decrease per one degree warming) in the low-level circulation (Fig. 12a, b). The statistical significances for both indices reach a level above $95 \%$ by Mann-Kendall rank statistics (MK) test (Kendall 1955). The AusSM is projected with a slight increase $(2.6 \%)$ in precipitation and an insignificant decrease (2.2\%) in the low-level circulation (Fig. 10b). In sum, the AAM precipitation (ASM and AusSM) will increase significantly, while the low-level wind circulation and vorticity associated with ASM will decrease significantly, but it is uncertain for the AusSM.

\subsection{The strength of the sub-monsoon system}

While the entire ASM has an overall trends in 21st century, it remains unknown how large these trends are in different 
(a) Land only

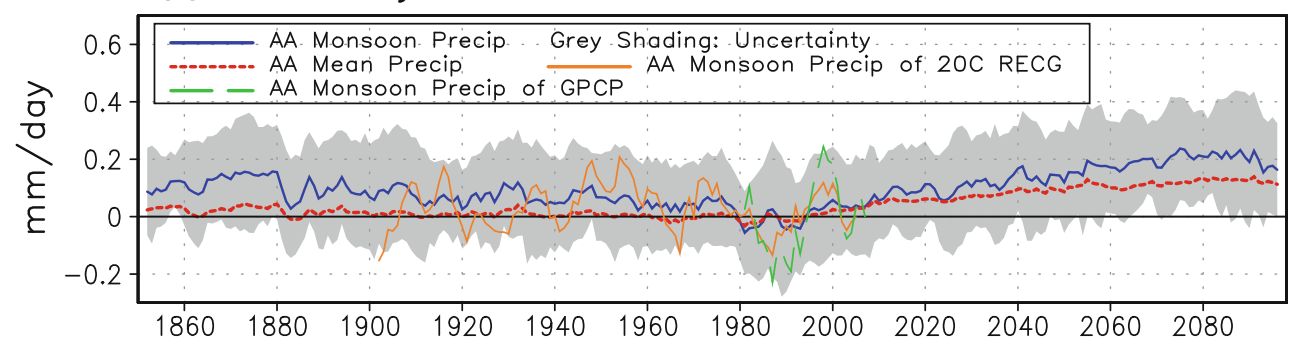

(b) Ocean only

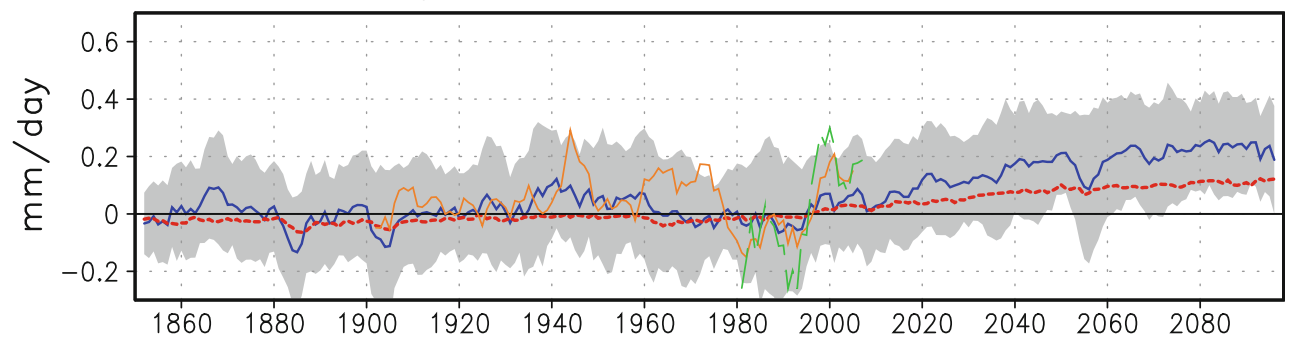

Fig. 9 Changes in (a) land and (b) oceanic monsoon rainfall over the AAM region using the B7MMM. The total monsoon precipitation domain was partitioned as land and oceanic monsoon domains. Shown are the time series of the local summer monsoon precipitation intensity (blue, $\mathrm{mm} \mathrm{day}^{-1}$ ) averaged for (a) land monsoon region and (b) ocean monsoon region (blue) and over the entire AAM domain $\left(40^{\circ}-180^{\circ} \mathrm{E}, 40^{\circ} \mathrm{S}-50^{\circ} \mathrm{N}\right.$, red). The orange curves show precipitation time series obtained from the merged statistical analyses of historical monthly precipitation anomalies (20C RECG) over the land and ocean region, respectively. The green curves are monsoon precipitation derived from GPCP data over the land and ocean region, respectively sub-monsoon regions. To this end, we examine the future trends for three sub-regions of the ASM. The definitions of the precipitation and circulation intensity indices for Indian, WNP, and EA summer monsoons are presented in Table 2. As seen from Figs. 11 and 12, the ISM and EASM precipitation will increase significantly by about $5.0 \%$ and $6.4 \%$ given one degree global warming, respectively, whereas the WNPSM rainfall will increase moderately by $2.9 \%$ given one degree global warming. The precipitation trends for all ASM sub-monsoon system are significant at $95 \%$ level. On the other hand, the Indian and WNP summer monsoon circulation intensities will decrease by $0.2 \%$ and $6.8 \%$, respectively. Notable is that the subtropical EASM circulation intensity will slightly increase against the previous results by CMIP3 models that suggests a significant decrease of EASM circulation (Tanaka et al. 2005; Ueda et al. 2006).

\subsection{The dominant mode of the interannual variation}

How will the interannual variability of the AAM system change is a question that is important for future climate prediction. We apply S-EOF to individual models for the last 26 years of 2070-2095 in comparison with the presentday (1980-2005) results shown in Figs. 4 and 5. It is first noted that there are no significant changes in the spatial distribution of the leading S-EOF mode (not shown).
However, there are several notable changes in the leading mode. First, most of models project weakening of the leading mode in the future shown in Fig. 13a. In particular, four of the seven best models (CanESM5, CCSM4, FGOALS-g2, and GISS-E2) predict significant weakening of explained variance. Second, the AAM-ENSO relationship will be increased significantly under the anthropogenic global warming despite of the decrease of its explained variance. Except FGOALS-g2, six of the seven best models project increase of the correlation coefficient between the leading PC and DJF Nino 3.4 SST index.

\section{Factors contributing to AAM change}

In addition to the low-level winds and vorticity, the ASM strength has been gauged by vertical shear of zonal winds, because monsoon circulation is characterized by a strong low-level westerly and upper-level easterly (Webster et al. 1998). Webster and Yang (1992) has proposed a vertical shear index for measuring the ASM strength: the U850 minus U200 averaged over South Asia (0-20 N, 40-110E). Figure 14a shows that a slightly modified Webster-Yang index exhibits no long-term trend in the 20C reanalysis data, and the B7MMM is in a gross agreement with the observation. However, this vertical shear index shows a significant decreasing trend in the 21 st century projection. 
Table 2 Definition of AAM precipitation and circulation indices for the entire system and subsystems

\begin{tabular}{|c|c|c|c|}
\hline & Precipitation intensity & Low-level circulation intensity & Correlation coefficient \\
\hline ISM & $10 \mathrm{~N}-30 \mathrm{~N}, 70 \mathrm{E}-105 \mathrm{E}$ & U850 (5N-15N, 40E-80E) minus U850 (25N-35N, 70E-90E) & 0.76 \\
\hline WNPSM & $12.5 \mathrm{~N}-22.5 \mathrm{~N}, 110 \mathrm{E}-150 \mathrm{E}$ & U850 (5N-15N, 100E-130E) minus U850 (20N-35N, 110E-140E) & 0.80 \\
\hline EASM & $22.5 \mathrm{~N}-45 \mathrm{~N}, 110 \mathrm{E}-135 \mathrm{E}$ & V850 (20N-40N, 120E-140E) & 0.70 \\
\hline $\begin{array}{l}\text { ASM } \\
\text { (entire Asia) }\end{array}$ & ISM + WNPSM + EASM & U850 (5N-20N, 60E-120E) minus U850 (20N-30N, 110E-140E) & 0.71 \\
\hline AusSM & $5 \mathrm{~S}-20 \mathrm{~S}, 110 \mathrm{E}-150 \mathrm{E}$ & U850 (0-15S, 90E-130E) minus U850 (20S-30S, 100E-140E) & 0.89 \\
\hline
\end{tabular}

Shown are the domains defined for computing local summer monsoon precipitation intensity indices and the corresponding low-level circulation indices for Indian (ISM), western North Pacific (WNPSM), East Asian (EASM), Australian (AusSM), entire Asian (ISM + WNPSM + EASM; ASM) monsoon systems, and the entire AAM system (ASM + AusSM)

(a) ASM

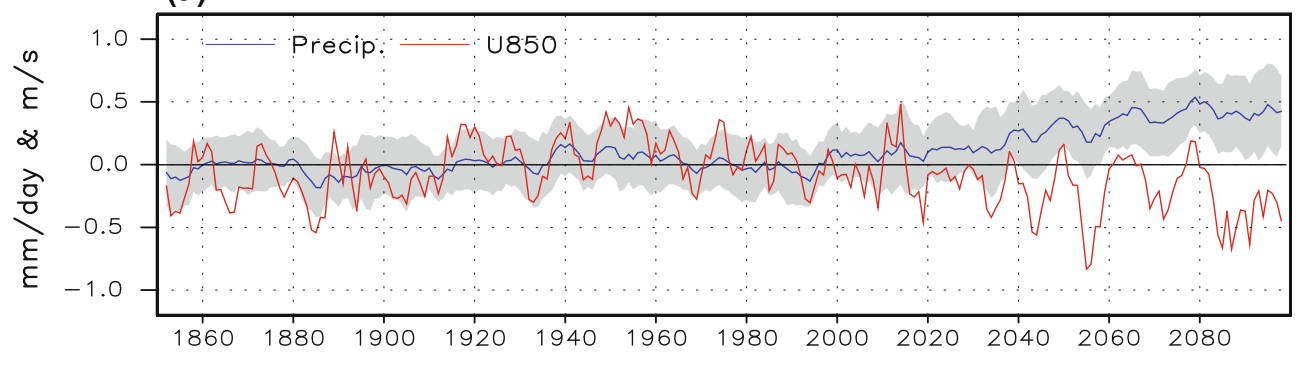

(b) AusSM

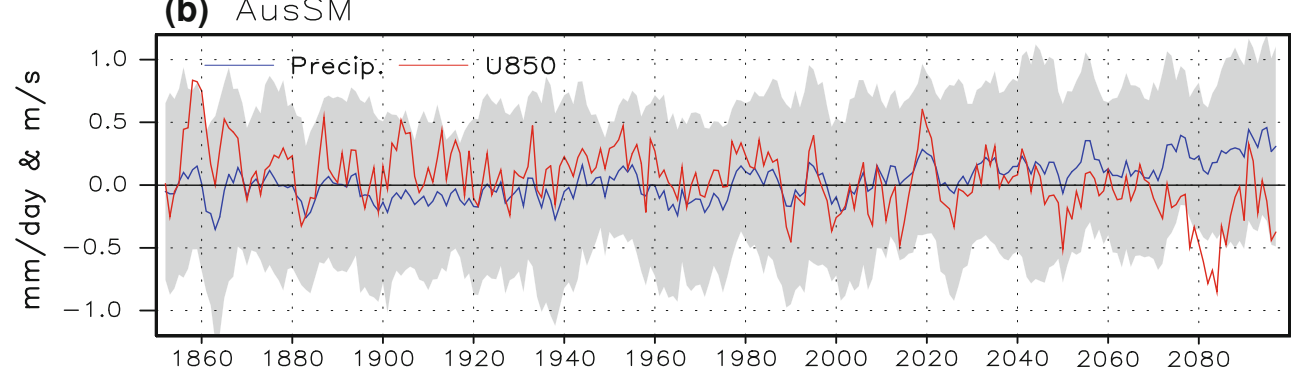

Fig. 10 Changes of the intensity of the AAM system as measured by (a) Asian summer monsoon (ASM) and (b) Australian summer monsoon (AusSM) precipitation indices. The ASM and AsuSM precipitation indices are defined as the area-mean precipitation rate (mm/day) in the Asian summer (JJAS) monsoon regions and Australian (DJFM) monsoon regions, respectively. The corresponding circulation indices for ASM and AusSM are defined by the meridional

This decreasing trend is consistent with the WNP summer monsoon low-level circulation changes (Figs 11b).

Why will the AAM precipitation increase while the circulations weaken? The greenhouse gas (GHG)-induced global warming has two opposing effects. On one hand, it causes an increase in the atmospheric water vapor that favors for increasing rainfall primarily by mean flow moisture convergence; on the other hand, it warms upper atmosphere more than the lower tropical atmosphere, thus increases atmospheric static stability, which tends to weaken the vertical motion and associated divergent and rotational circulations, thus decreasing precipitation. The shear at $850-\mathrm{hPa}$ zonal winds $(\mathrm{m} / \mathrm{s})$ (Table 2$)$. The shading denotes the B7MME's uncertainties for the precipitation indices which are determined by one standard deviation of the individual models' departure from the MME. The anomaly was obtained from the climatology of 1980-2005. 5-year moving averaging was applied to all time series

increase in atmospheric static stability is prominent in both the upper and lower troposphere (Fig. 14d, e). As a result, the monsoon low-level circulation and vertical wind shear will weaken mainly over the WNP monsoon region. This weakening circulation tends to reduce the precipitation increase, so that the rate of increasing precipitation is smaller than the rate of increasing water vapor (Lee and Wang 2012). While the increase in precipitation tends to enhance the circulation, the stabilization of the atmosphere tends to prevail, so that the circulation will have a decreasing trend in general. From Fig. 11, we see that over the India and the East Asia the precipitation trends are 
(a) ISM

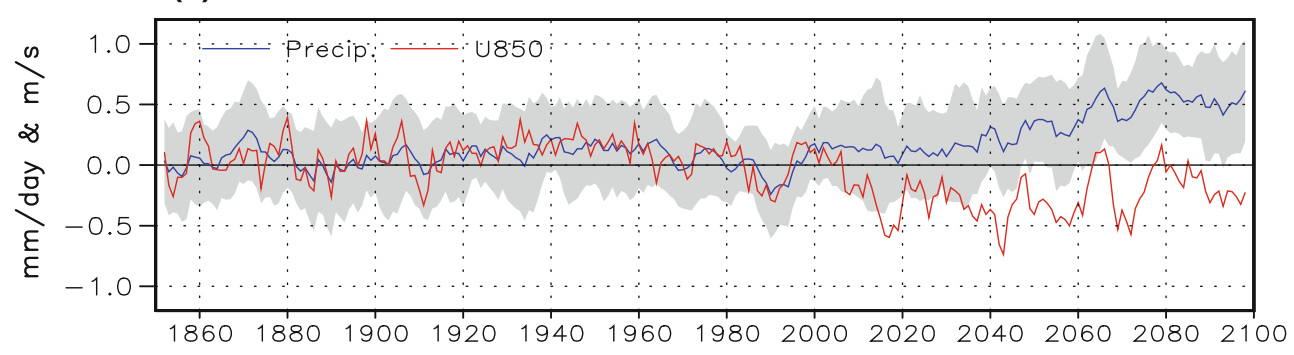

(b) WNPSM

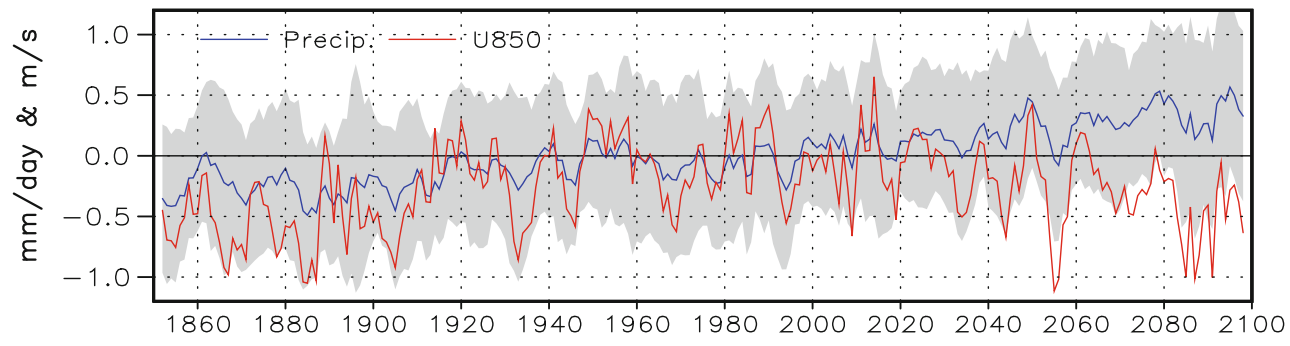

(c) EASM

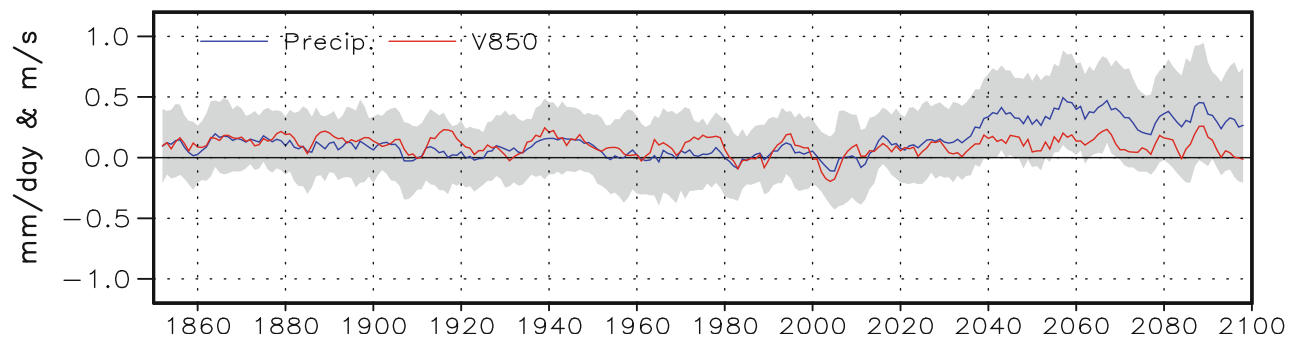

Fig. 11 Changes of the strength of the sub-monsoon systems: The same as in Fig. 10 except for each sub-monsoon of the Asian summer monsoon for (a) ISM, (b) WNPSM, and (c) EASM

much larger than that over the WNPSM. Correspondingly, the low-level circulation over India has a weak decreasing and that over East Asia has even weak increasing trend while the WNPSM circulation has a significant decreasing trend. Nevertheless, these two opposing factors are insufficient to explain the hemispheric differences: $4.5 \%$ increase in the ASM precipitation and $2.6 \%$ increase given one degree global warming in Australian monsoon precipitation.

Wang et al. (2012), based on analysis of the observed changes of the global monsoon precipitation, found two additional factors that may control AAM precipitation in the future. One is the enhanced land-ocean thermal contrast as noted by Sun et al. (2010). This "warm land-cold ocean" mechanism results in a rising sea level pressure (SLP) in the Pacific (relatively cooling) and lowering SLP over the Eurasian continent. This is confirmed by the time series shown in Fig. 14c. The trend pattern in SLP favors moisture transport from Pacific to AAM regions and increases AAM precipitation in both hemisphere. Another factor is the enhanced 'warm northern hemisphere (NH)-cool southern hemisphere (SH)' which is shown by the time series in Fig. 14b. This hemispheric thermal contrast trend would favor cross-equatorial flows from the $\mathrm{SH}$ to $\mathrm{NH}$ which favors for ASM but weakens AusSM. These two additional factors together may explain why the AusSM precipitation does not increase as much as the ASM precipitation.

\section{Summary}

We investigated the future changes of the AAM projected by 20 coupled models that participated in CMIP5. A metrics for evaluation of the model's performance in AAM climatology and variability is designed. It is noted that the CMIP5 models are more skillful than the CMIP3 models for the AAM metrics used in this study. The seven best models in reproducing the AAM precipitation climatology and variability are selected in order to get more reliable MMM for reconstruction and future projection.

The B7MMM projected future changes of the AAM system are summarized as follows. 


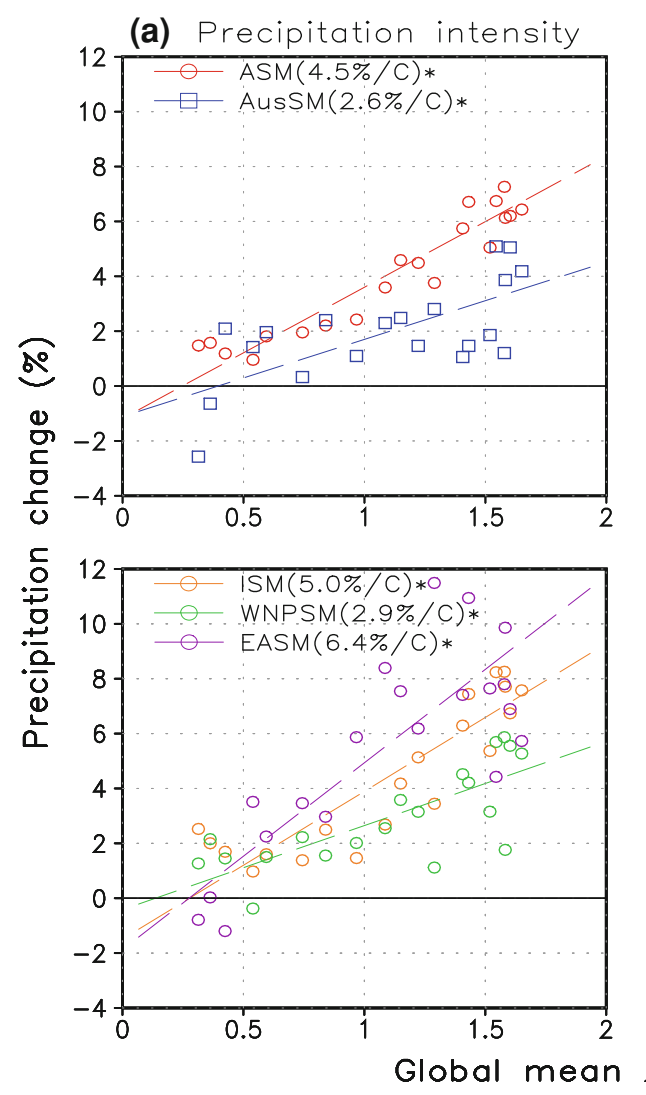

Fig. 12 Scatter diagram showing the projected changes in precipitation and circulation intensities in the twenty-first century as functions of global mean $2 \mathrm{~m}$ air temperature over the ASM, AusSM, and sub-monsoon areas. 5-year average was applied. The percentage (b) Circulation intensity

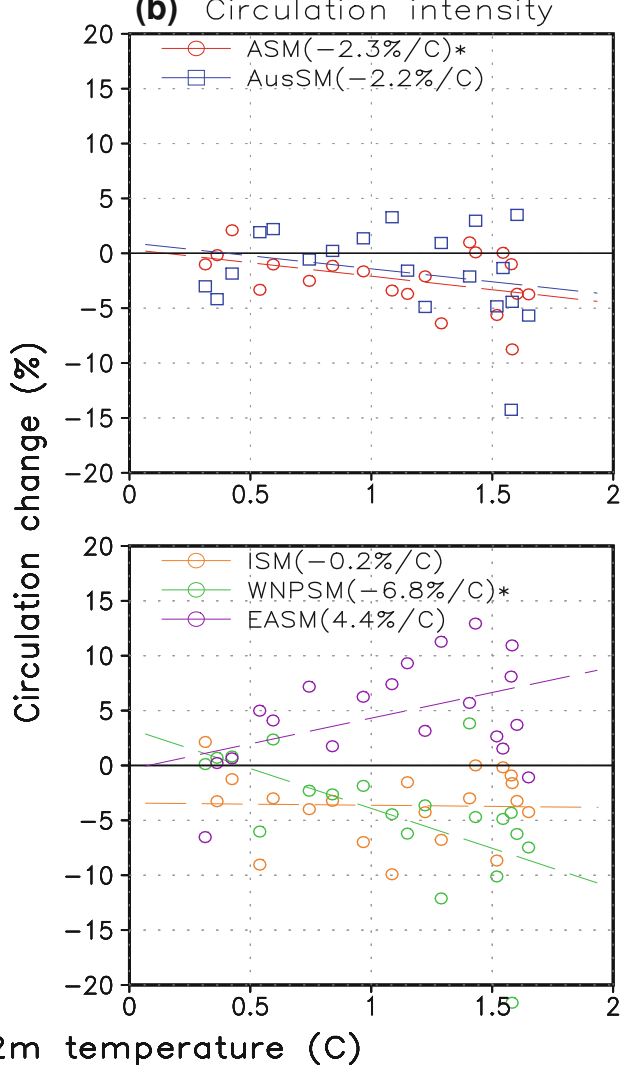

rate in the parenthesis indicates the change with respect to the present day (1980-2005) given $1^{\circ}$ warming and the values of the trend exceeding $95 \%$ confidence level are marked by * (a) Explained variance

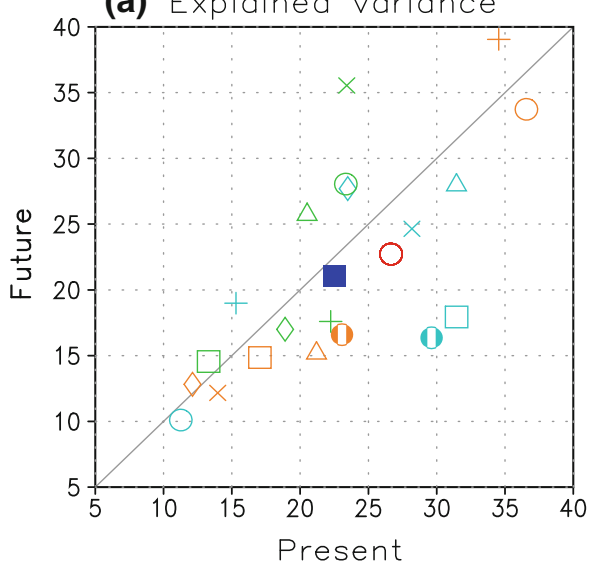

(b) AAM-ENSO relationship

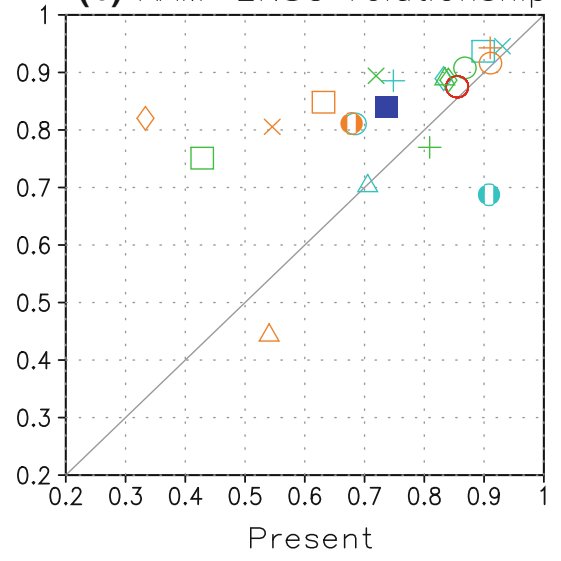

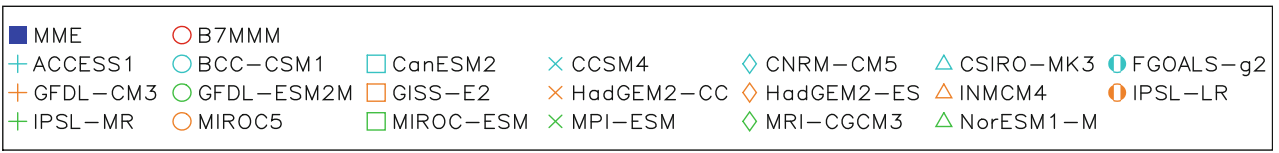

Fig. 13 Scatter diagram showing (a) percentage variance (\%) of the leading S-EOF mode and (b) correlation coefficient between the leading PC and the Nino3.4 SST index for the present period
1980-2005 (abscissa) versus the future period 2070-2095 (ordinate) simulated by CMIP5 20 models 
(a) Modified Webster and Yang index

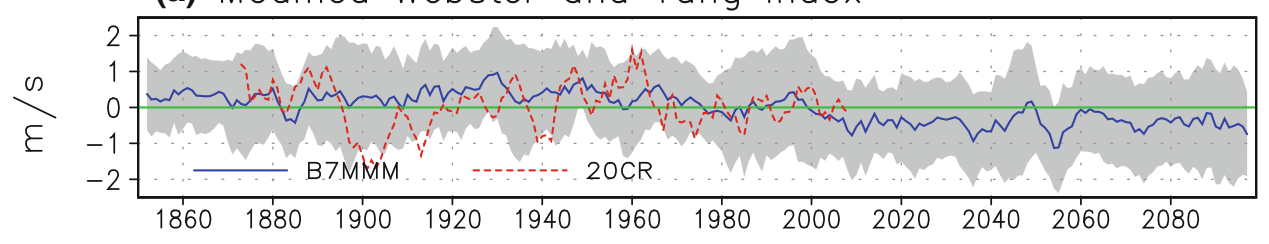

(b) $\mathrm{NH}$ and $\mathrm{SH}$ Temperature difference

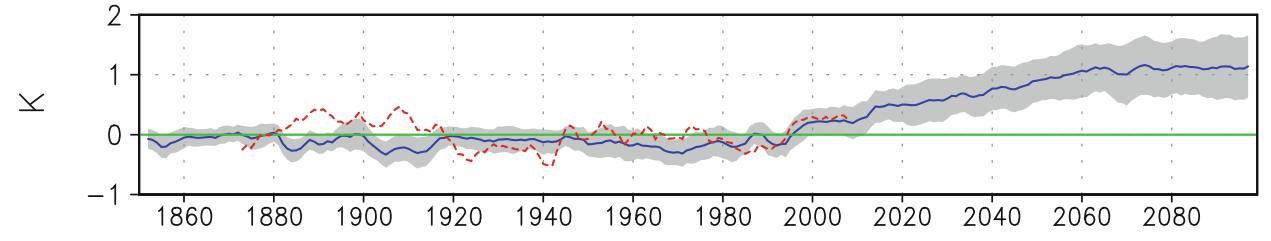

(c) SLP difference between the Pacific and Eurasia

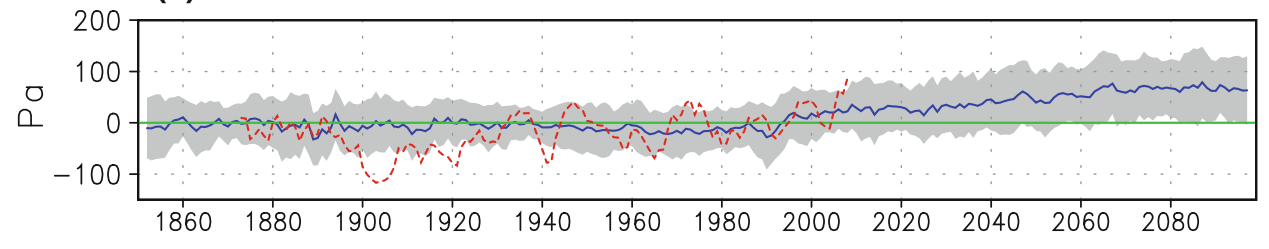

(d) Static stability (T500-T200)

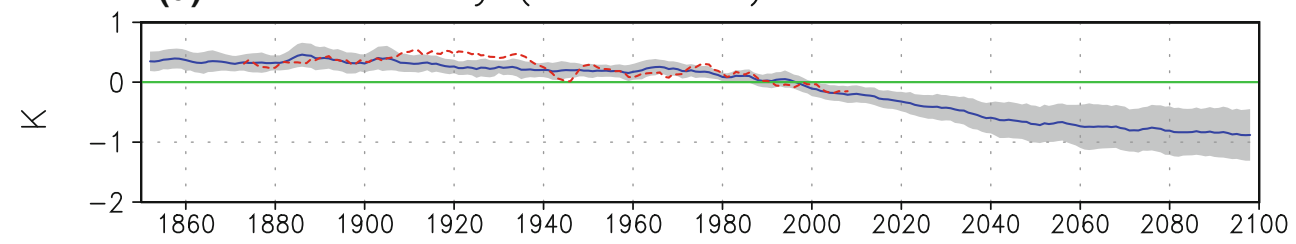

(e) Static stability (T850-T500)

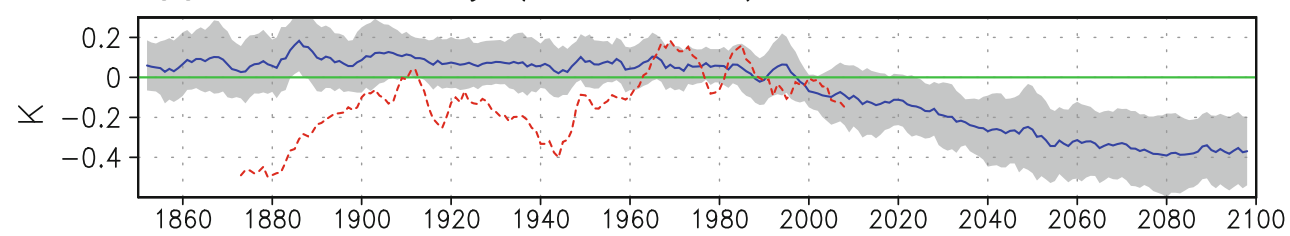

Fig. 14 Factors contributing to Asian summer monsoon changes: Time series of the (a) modified Webster-Yang vertical wind shear index for the Asian summer monsoon (JJAS) [(U850-U200), $0^{\circ}-$ $\left.20^{\circ} \mathrm{N}, 60^{\circ} \mathrm{E}-120^{\circ} \mathrm{E}\right],(\mathbf{b})$ the northern hemisphere $(\mathrm{NH})$ and southern hemisphere $(\mathrm{SH})$ temperature difference $\left[\left(\mathrm{T} 2 \mathrm{~m}, 20^{\circ} \mathrm{N}-60^{\circ} \mathrm{N}, 40^{\circ} \mathrm{E}-\right.\right.$ $\left.\left.120^{\circ} \mathrm{E}\right)-\left(\mathrm{T} 2 \mathrm{~m}, 40^{\circ} \mathrm{S}-0^{\circ}, 40^{\circ} \mathrm{E}-120^{\circ} \mathrm{E}\right)\right]$, (c) The sea level pressure (SLP) difference between the Pacific and Eurasian continent. [SLP $\left(20^{\circ} \mathrm{S}-20^{\circ} \mathrm{N}, \quad 150^{\circ} \mathrm{E}-90^{\circ} \mathrm{W}\right)$ minus SLP $\left(10^{\circ}-50^{\circ} \mathrm{N}, 0^{\circ}-90^{\circ} \mathrm{E}\right)$,

- The AAM domain will not change significantly (it shows an increase by $7.8 \%$ but this increase is less than the inter-model spread and models' mean bias), albeit there is a local tendency for westward extension of the monsoon regime. The proportion of local summer rainfall to annual mean precipitation, however, will increase over Australian monsoon and subtropical Asian monsoon but drops in the southern edges of the Asian monsoon. (d) static stability at upper level $\left[(\mathrm{T} 500-\mathrm{T} 200), 0^{\circ}-15^{\circ} \mathrm{N}, 60^{\circ} \mathrm{E}-\right.$ $\left.120^{\circ} \mathrm{E}\right]$, and (e) static stability at lower level [(T850-T500), $0^{\circ}-15^{\circ} \mathrm{N}$, $\left.60^{\circ} \mathrm{E}-120^{\circ} \mathrm{E}\right]$. The time series are obtained from the B7MMM for the historical run period (1850-2005) and the RCP 45 run period (2006-2100) along with 20th C reanalysis (20CR). Gray shading indicates MMM's uncertainty. The anomalies were obtained from the climatology of 1980-2005. 5-year moving averaging was applied to all time series

- The spatial structure of the leading S-EOF mode of AAM precipitation in 20-model MME and B7MMM will not change appreciably, but in future the AAMENSO relationship will be increased significantly under the anthropogenic global warming despite the slight decrease of its explained variance.

- The total AAM precipitation and circulation have no long-term trends in the historical period from 1850 to 2005. However, by the end of the $21^{\text {st }}$ century the AAM 
precipitation will increase significantly (by about $4.5 \% /{ }^{\circ} \mathrm{C}$ ) mainly due to increases in ISM and EASM (the increases in WNPSM is about $2.9 \% /{ }^{\circ} \mathrm{C}$ and the AusSM by $\left.2.6 \% /{ }^{\circ} \mathrm{C}\right)$. Similar to the total AAM precipitation the land and oceanic monsoon rainfall have comparable increasing trends. However, the lowlevel winds and vorticity with the AAM system will all decrease by about $2.3 \%$ due mainly to the weakening of the tropical monsoon circulations (the ISM, WNPSM, and AusSM). The notable feature is that EA subtropical summer monsoon circulation will slightly increase due to enhanced zonal thermal contrast and SLP difference against the previous results by CMIP3 models that suggests a significant decrease of EASM circulation.

The future trends in the AAM system are a consequence of a combination of a number of processes that contribute to the change of the interactive monsoon precipitation and circulations. These processes include the opposing effects of the greenhouse gases warming induced water vapor increase and static stability increase. The effect of the increasing water vapor may be compensated by the negative impact of the increased stability on the AAM precipitation. The resultant change in the total AAM precipitation is less than what is expected from the increasing water vapor content. But these two factors alone cannot explain the north-south asymmetry in AAM rainfall change. It is conceivable that the GHG warming induced horizontal thermal contrasts are also important for understanding the monsoon future changes (Wang et al. 2012). The "warm land-cool ocean" favors the entire AAM precipitation increase by generating an east-west asymmetry in the SLP field. On the other hand, the warm $\mathrm{NH}$-cool SH generates hemispheric SLP difference that favors the ASM but reduces the Australian summer monsoon rainfall. As a result the ASM will increases much more strongly than the Australian summer monsoon rainfall. Detailed budget studies and more numerical experiments are needed to further pin down the precise roles of the proposed factors.

Acknowledgments This work was supported by the National Research Foundation of Korea (NRF) through a Global Research Laboratory (GRL) grant (MEST 2011-0021927) and IPRC, which is in part supported by JAMSTEC, NOAA, and NASA. We acknowledge the World Climate Research Programme's Working Group on Coupled Modeling, which is responsible for CMIP, and we thank the climate modeling groups listed in Table 1 of this paper for producing and making available their model output. For CMIP the U.S. Department of Energy's Program for Climate Model Diagnosis and Intercomparison provides coordinating support and led development of software infrastructure in partnership with the Global Organization for Earth System Science Portals. 20th Century Reanalysis V2 data provided by the NOAA/OAR/ESRL PSD, Boulder, Colorado, USA, from their Web site at http://www.esrl.noaa.gov/psd. This is the SOEST publication number 8927 and IPRC publication number 980 .
Open Access This article is distributed under the terms of the Creative Commons Attribution License which permits any use, distribution, and reproduction in any medium, provided the original author(s) and the source are credited.

\section{References}

Compo GP, Whitaker JS, Sardeshmukh PD et al (2011) The twentieth century reanalysis project. Q J R Meteor Soc 137:1-28

Ding YH (1994) Monsoons over China. Kluwer Academic, Dordrecht, $p 419$

Ding QH, Wang B (2005) Circumglobal teleconnection in the Northern Hemisphere summer. J Clim 18:3483-3505

Enomoto T, Hoskins BJ, Matsuda Y (2003) The formation mechanism of the Bonin high in August. Q J R Meteor Soc 129:157-178

Guo QY, Wang JQ (1988) A comparative study on summer monsoon in China and India (in Chinese). J Trop Meteor 4:53-60

Ha KJ, Chu JE, Lee JY, Wang B et al (2012) What causes cool summer over northern Central Asia, East Asia, and central North America during 2009? Environ Res Lett 7:44015

Hamada JI, Yamanaka MD, Matsumoto J, Fukao S, Winarso PA, Sribimawati T (2002) Spatial and temporal variations of the rainy season over Indonesia and their link to ENSO. J Meteor Soc Jpn 80:285-310

Huang R, Wu Y (1989) The influence of ENSO on the summer climate change in China and its mechanism. Adv Atmos Sci 6:21-32

Huffman GJ, Bolvin DT, Adler RF (2011) Last updated GPCP Version 2.2 combined precipitation data set. WDC-A, NCDC, Asheville, NC. Dataset accessed at http://www.ncdc.noaa.gov/ oa/wmo/wdcamet-ncdc.html

Kendall MG (1955) Rank correlation methods. Charles Griffin \& Co., London

Kripalani RH, Singh SV (1993) Large-scale aspects of India-China summer monsoon rainfall. Adv Atmos Sci 10:72-84

Kripalani RH, Oh JH, Kulkarni A, Sabade S, Chaudhari HS (2007a) South Asian summer monsoon precipitation variability. Coupled climate model simulations and projections under IPCC AR4. Theor Appl Climatol 90:133-159

Kripalani RH, Oh JH, Chaudhari HS (2007b) Response of the East Asian summer monsoon to doubled atmospheric $\mathrm{CO}_{2}$ : coupled climate model simulations and projections under IPCC AR4. Theor Appl Climatol 87:1-28

Lau KM (1992) East Asian summer monsoon rainfall variability and climate teleconnection. J Meteor Soc Jpn 70:211-240

Lee JY, Wang B (2012) Future change of global monsoon in the CMIP5. Clim Dyn (in press). doi:10.1007/s00382-012-1564-0

Lee JY, Wang B, Kang IS, Shukla J et al (2010) How are seasonal prediction skills related to models' performance on mean state and annual cycle? Clim Dyn 35:267-283

Lee JY, Wang B et al (2011) How predictable is the Northern Hemisphere summer upper-tropospheric circulation? Clim Dyn 37:1189-1203

Liang P-D (1988) Indian summer monsoon and rainfall in North China in summer (in Chinese). Acta Meteor Sinica 46:75-81

Meehl GA (1987) The annual cycle and interannual variability in the tropical Pacific and Indian Ocean regions. Mon Weather Rev 115:27-50

Meehl GA, Stocker TF et al (2007) Global climate projections. In: Solomon S et al (eds) Climate change 2007: the physical science basis. Cambridge University Press, Cambridge, pp 749-830 
Mooley DA, Parthasarathy B (1984) Fluctuations in all-India summer monsoon rainfall during 1871-1978. Clim Change 6:287-301

Nitta T (1987) Convective activities in the tropical western Pacific and their impact on the Northern Hemisphere summer circulation. J Meteor Soc Jpn 65:373-390

Ramage CS (1971) Monsoon meteorology. Academic, New York, p 296

Shukla J (1987) Interannual variability of monsoons. In: Fein JS, Stephens PL (eds) Monsoons. Wiley, New York, pp 399-463

Smith TM, Reynolds RW, Peterson TC, Lawrimore J (2008) Improvements to NOAA's historical merged land-ocean surface temperature analysis (1880-2006). J Clim 21:2283-2296

Smith TM, Arkin PA, Sapiano MRP (2010) Merged statistical analyses of historical monthly precipitation anomalies beginning 1990. J Clim 23:5755-5770

Sperber KR, Annamalai H, Kang IS, Kitoh A, Moise A, Turner A, Wang B, Zhou T (2012) The Asian summer monsoon: an intercomparison of CMIP5 vs CMIP3 simulations of the late 20th century. Clim Dyn (in press). doi:10.1007/s00382-012-1607-6

Sun Y, Ding YH, Dai A (2010) Changing links between South Asia summer monsoon circulation and tropospheric land-sea thermal contrasts under a warming scenario. Geophy Res Lett 37:L02704

Tanaka HL, Ishizaki N, Nohara N (2005) Intercomparison of the intensities and trends of Hadley, Walker and monsoon circulations in the global warming predictions. Sci Online Lett Atmos $1: 77-80$

Taylor KE, Stouffer RJ, Meehl GA (2012) An overview of CMIP5 and the experiment design. Bull Am Meteor Soc 93:485-498

Ueda H, Iwai A, Kuwako K, Hori ME (2006) Impact of anthropogenic forcing on the Asian summer monsoon simulated by 8 GCMs. Geophys Res Lett 33:L06703. doi:10.1029/2005GL025336

Wang B (1994) Climatic regimes of tropical convection and rainfall. J Clim 7:1109-1118

Wang B (2006) The Asian monsoon. Preface, Springer, Praxis, p 779

Wang B, Ding QH (2008) Global monsoon: dominant mode of annual variation in the tropics. Dyn Atmos Oceans 44:165-183

Wang B, Wu R, Lau KM (2001) Interannual variability of Asian summer monsoon: contrast between the Indian and western North Pacific-East Asian monsoons. J Clim 14:4073-4090

Wang B, Clemons SC, Liu P (2003a) Contrasting the Indian and East Asian monsoons: implications on geologic timescales. Mar Geol 201:5-21
Wang B, Wu R, Li T (2003b) Atmosphere-warm ocean interaction and its impact on Asian-Australian monsoon variation. J Clim 16:1195-1211

Wang B, Yang J, Zhou T, Wang B (2008a) Interdecadal changes in the major modes of Asian-Australian monsoon variability: strengthening relationship with ENSO since the late $1970 \mathrm{~s}$. J Clim 21:1771-1789

Wang B, Lee JY, Kang IS, Shukla J et al (2008b) How accurately do coupled climate models predict the leading modes of AsianAustralian monsoon interannual variability? Clim Dyn 30:605-619

Wang B, Kim HJ, Kikuchi K, Kitoh A (2011) Diagnostic metrics for evaluation of annual and diurnal cycles. Clim Dyn 37:941-955

Wang B, Liu J, Kim HJ, Webster PJ, Yim SY (2012) Recent changes of the global monsoon precipitation (1979-2008). Clim Dyn 39:1123-1135

Wang B, Xiang B, Lee JY (2013) Subtropical high predictability establishes a promising way for monsoon and tropical storm predictions. PNAS 110:2718-2722

Webster PJ (1987) The variable and interactive monsoon. In: Fein and Stephens (eds) Monsoons. Wiley New York, pp 269-330

Webster PJ, Yang S (1992) Monsoon and ENSO: selectively interactive systems. Q J R Meteor Soc 118:877-926

Webster PJ, Magana VO, Palmer TN, Shukla J, Tomas RA, Yanai M, Yasunari T (1998) Monsoons: processes, predictability, and the prospects for prediction. J Geophys Res 103:14451-14510

Wu R, Wang B (2000) Interannual variability of summer monsoon onset over the western North Pacific and the underlying processes. J Clim 13:2483-2501

Xie P, Arkin PA (1997) Global precipitation: a 17-year monthly analysis based on gauge observations, satellite estimates, and numerical model outputs. Bull Am Meteor Soc 78:2539-2558

Yasunari T, Suppiah R (1988) Some problems on the interannual variability of Indonesian monsoon rainfall. In: Theon JS, Fugono $\mathrm{N}$ (eds) Tropical rainfall measurements. A Deepak Publishing, Hampton, pp 113-122

Zhou TJ, Yu RC (2005) Atmospheric water vapor transport associated with typical anomalous summer rainfall patterns in China. J Geophys Res 110:D08104. doi:10.1029/2004JD005413 